\title{
Investigations of Diesel Injector Deposits Characterization and Testing
}

\author{
Author, co-author (Do NOT enter this information. It will be pulled from participant tab in \\ MyTechZone) \\ Affiliation (Do NOT enter this information. It will be pulled from participant tab in MyTechZone)
}

\begin{abstract}
Over the last decade, there has been an impetus in the automobile industry to develop new diesel injector systems, driven by a desire to reduce fuel consumption and proscribed by the requirement to fulfil legislation emissions. The modern common-rail diesel injector system has been developed by the industry to fulfil these aspirations, designed with ever-higher tolerances pressures, which have led to concomitant increases in fuel temperatures after compression with reports of fuel temperatures of $\sim 150^{\circ} \mathrm{C}$ at $1500-2500$ bar. This engineering solution in combination with the introduction of Ultra Low Sulphur diesel fuel (ULSD) has been found to be highly sensitive to deposit formation both external injector deposits (EDID) and internal (IDID). The deposits have caused concerns for customers with poor spray patterns misfiring injector malfunction and failure producing increased fuel consumption and emissions. The importance to the industry of understanding the nature of diesel injector deposits has led to significant research in this area with a number of industry tests being developed. However, the introduction of new generation fuels e.g. hydrogenated vegetable Oil (HVO) and the reports of injector problems such as “abrasive particles” in Europe continue to stimulate investigation. The interest in characterizing diesel injector deposits has also seen a number of recent contributions being published. Many of these reports describe analyses that either consider only the surface of deposits or use methods which destroy any provenance. In this paper, we will describe the latest data from the deployment of modern analytical techniques to characterize these deposits. As a further contribution to the understanding of diesel injector deposits, this paper will describe the use of Principal Component Analysis (PCA) in conjunction with Time of Flight Secondary Ion Mass spectrometry (ToF-SIMS) to determine trends in IDID chemistries worldwide. The application of the ToF-SIMS technique to EIDS will be described. The latest industry standard engine tests will be discussed with regard to the chemistries involved and the latest advances in the application of a new generation of deposit control additives (DCA) will be described.
\end{abstract}

\section{Introduction}

Rudolf Diesel's first patent of the diesel engine process in1892 revealed an engine which would run on a suite of fuels [1]. From a historical perspective there has been a move away from this allencompassing concept to a much narrower tolerance on both fuels Page 1 of 20 and the diesel system, driven by technical change forced in turn by legislation. The occurrence of deposit formation in diesel systems, filter, injectors, and common rails has mirrored this technical innovation. There are number of reviews of this in the literature [2-5]. In this paper we will highlight just some of the major issues that have challenged the industry and the way the industry has tried to meet them as well as describing some of the latest research in the area. The legislative drive has been continuous for many years, and in the present climate does not show any signs of abating [6-11] effecting automotive first and now expanding into locomotive [9] and more recently marine industries $[10,11]$ The growing use of common rail injector systems and the introduction of ULSD, low Sulphur marine fuels and biofuels are the major factors in this technological drive. Their introduction into each industry sector has led to unintended consequences [12-19], with changes to fuel solubilization, stability, in conjunction with increased injector tolerances that continue to advance, resulting in filter and injector deposit formation. As each technology has striven to achieve legislation driven emission requirements the area has become more complex. The diesel engine is a significant part of the worldwide powertrain fleet, and injector deposits continue to be reported .Here we will briefly describe the historical background and then the latest engine test and analytical developments which are providing data to characterize, measure and mitigate fuel injector deposits.

\section{Excerpts from History: Engine Testing}

In the early twentieth century the majority of the diesel engines in use were of the indirect injection (IDI) type. This type of engine was prone to soot formation producing smoke noise and increased exhaust emissions. Coking occurred due to the combustion gases being forced into the nozzle. Coking at the critical point of pilot injection delayed fuel entering the combustion chamber, which increased ignition delay. The industry response was via the industry body The Cocoordinating European Council (CEC), namely the CEC F-23-A-01 Peugeot XUD9 A/L [20] engine test. Representative of 1990's technology, Euro $1 \& 2$, this test is still used today. The amount of carbon coking in the Injector Nozzle was measured as a percentage of Loss of Air Flow from start of test. The test cycle is shown in Figure 1. It was found to be very robust when assessing the nozzle coking propensity of fuels and it is also a recognized test for assessing DCA effectiveness in coking prevention. The introduction of the common rail diesel injector engines again in response to emission regulations and the concurrent production of filter and injector deposits saw the industry respond with the CEC F-98-08 DW10B Direct Injection Nozzle Coking Engine Test [20]. The test cycle is high load as this 
was found to be the driving conditions that promoted deposits Figure 2.The fuel is dosed with zinc neodecanoate at $1 \mathrm{ppm}$ to promote deposit formation. The test cycle is 32 hours in length with $4 \times 8$ running periods with a 4 hour soak thus yielding a 44 hour total test time.

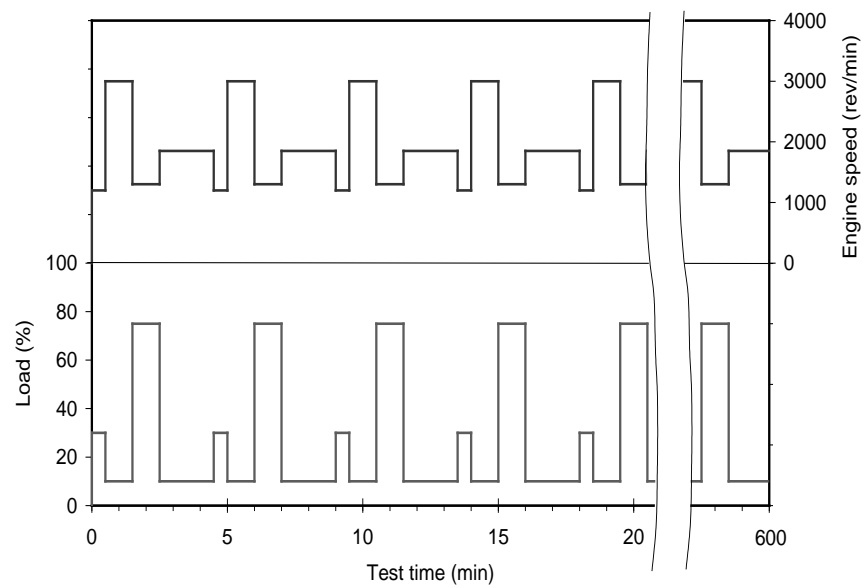

Figure 1. 10 hour XUD-9 A/L test cycle. [21]

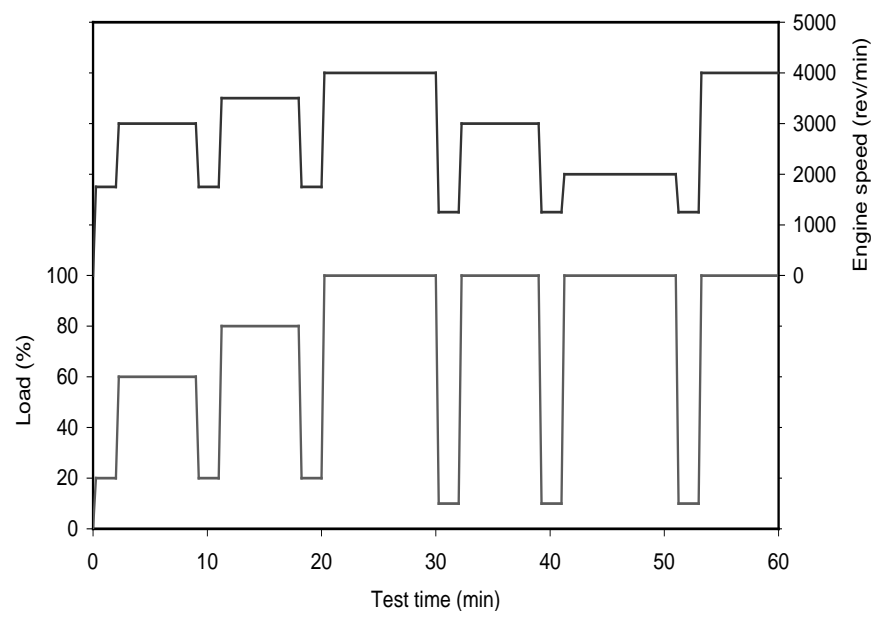

Figure 2 DW10B test cycle. [22] Direct Injection, Common Rail Diesel Engine Nozzle Coking Test Cycle

The measurement of power loss due to deposit formation is the indicator in this test. European studies have found a zinc content in the fuel of vehicles which have suffered power loss with the zinc is thought to originate from the fuel distribution system and some vehicle components.

\section{Excerpts from History: Analytical Testing}

The understanding of deposits using analytical chemistry mirrored the development of the engine tests described above as the industry worked to understand the problems. The study of pintle IDI injector was studied by Montagne, [23] Figure 3. Using Scanning Electron Microscopy (SEM) in addition to other techniques. Research in the area continues today [24].

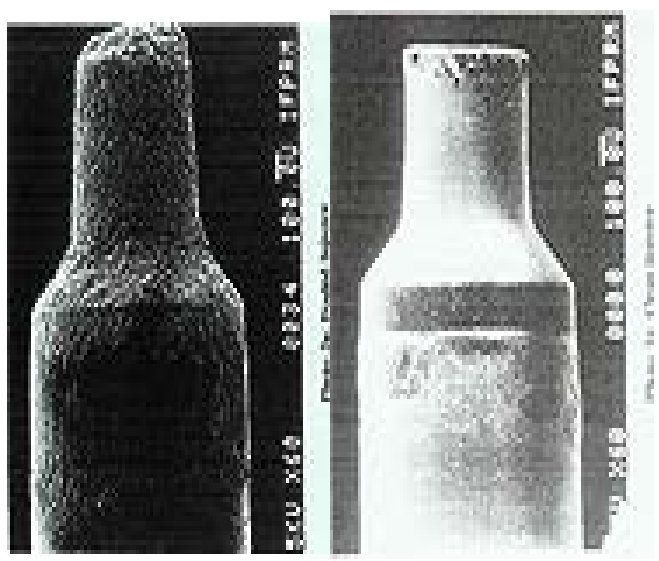

Figure 3. Clean and coked injector pintles

The introduction of legislation driven Ultra Low Sulfur diesel (ULSD) in the US and Europe in 2005-2006, and biodiesel along with the rise in the use of common rail injection systems saw initially problems with blocked fuel filters then injector problems such as no start and drivability issues. Injector deposits have been found in a number of locations in the injector, on the nozzle tip and in the spray holes external injector deposits (EDID) and since around 2008 internally on the push rod, the upper and lower springs and the needle. Though investigated for some time, these internal injector deposits (IDID) continue to be studied by groups worldwide because of their importance to the industry and a need to understand fully their nature [25-33]. Initial analysis by a number of groups contributed to identifying the deposits formed, leading to their classification in six distinct groups:

- $\quad$ Carbonaceous: carbon based black in color.

- $\quad$ Amides: polymeric and brown in color.

- Inorganic Salts: For example sodium chloride or sodium sulfate.

- $\quad$ Aged Fuel Deposits: "Sticky” residues possibly of bio origin.

- $\quad$ Lacquer based: Appear as multi-colored patterns indicating thin films of varying thickness.

- Carboxylate salts: Generally off-white in color and are usually sodium or calcium based.

Their origins have been attributed to a number of sources which continue to be added to, Figure 4. The figure shows in red those sources of deposit forming mechanisms associated with temperature and pressure rises resulting from the introduction of common rail diesel injector systems. The sources colored green are indicative of fuel component changes, fuel solubilization capability, housekeeping, poor manufacturing standards, and materials of construction and water presence. 


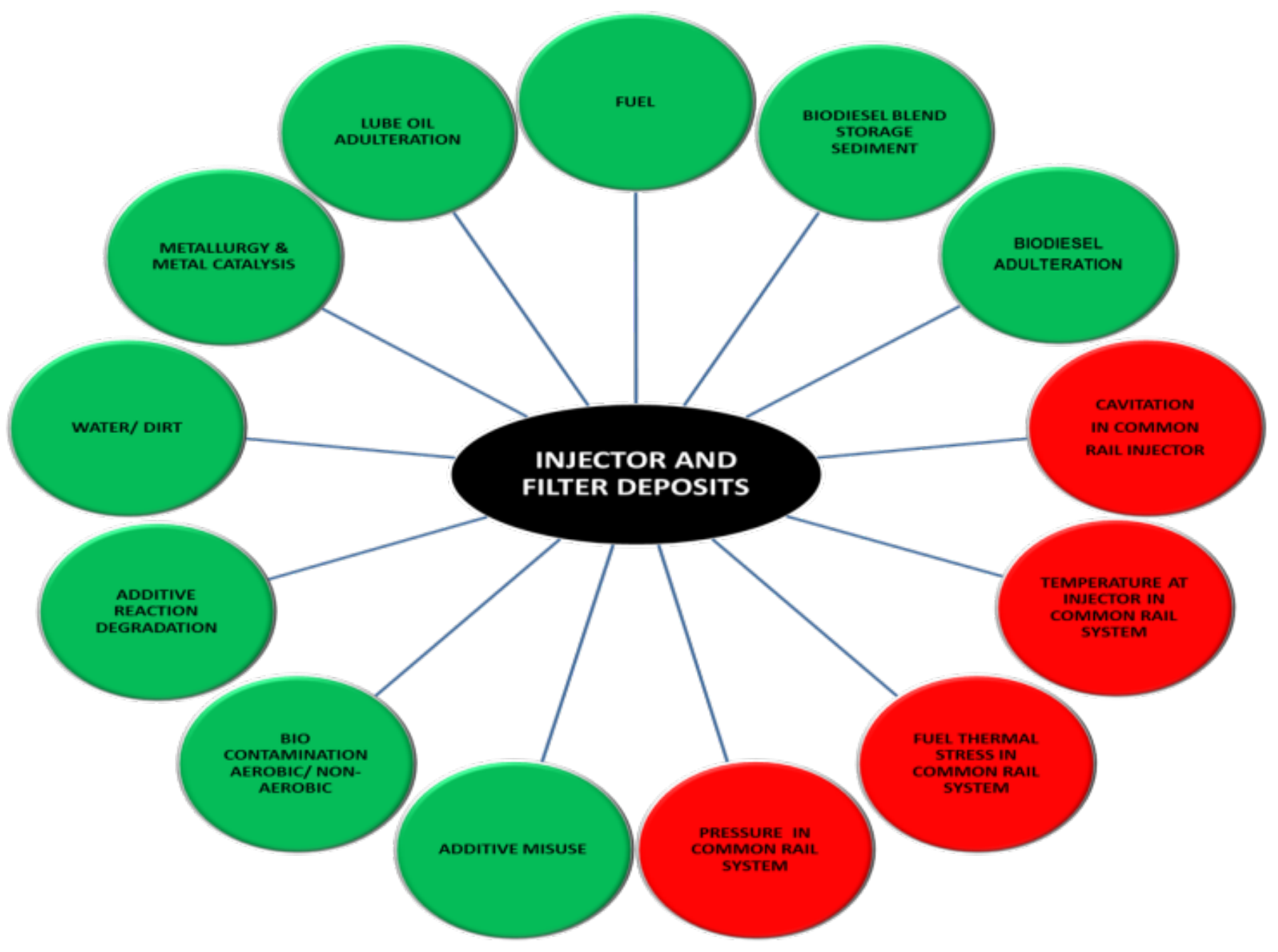

Figure 4 Sources of Diesel Injector Deposits.

The first studies to identify IDID were by Ullmann and Caprotti, et al [34]. These showed the presence of metal carboxylates from sodium and mono-acid lubricity additives as well as amide type deposits using Fourier Transform Infra-red Spectroscopy (FTIR) and Gel Permeation Chromatography (GPC). The amide deposits were postulated to come from a polyisobutylene succinimide (PIBSI) detergent of unknown provenance. Later work by Reid and Barker using DW10B, GPC, FTIR, and The Jet Fuel Thermal Oxidation Tester or JFTOT (ASTM D3241), showed non-commercial low molecular weight PIBSIs were responsible for the deposit and that the quality of manufacture of PIBSI detergents is of paramount importance [35]. The importance of the manufacturing process was further promoted by Fang [36]. The carboxylate deposits are more

Page 3 of 20 complex in their origins. Metals in diesel fuel react with carboxylic acids in the fuel to yield salts. Metals that have been found in diesel fuel IDIDs include sodium calcium, tin, iron and zinc. Of these sodium is the most abundant. Possible sources include caustic wash in petroleum refineries, biodiesel production, storage tank water bottoms and transportation e.g. via barges. The organic acids may originate from fuel contamination, microbiological contamination, biodiesel, degraded biodiesel or organic acids added to the fuel as corrosion or lubricity additives [37-45]. Some carboxylate salts have been noted as being insoluble in fuel at low temperatures and it is only when the high temperature and pressure regime of the common rail injector is encountered that deposition occurs, [19]. Carbonaceous deposits were found by Barker et al using Hydropyrolysis, FTIR, and studied further with ToF-SIMS and 
Temperature Programmed Oxidation. (TPO), [2, 46-47] Lau et al reported further evidence for aromatic ring compounds in the IDID. [48]. All the data shows aromatic ring species beyond six rings in structure which are postulated as intermediates between the initial fuel degradation and graphene-like deposits [뜨]. Unlike metal carboxylates which are excursion deposits that is to say deposits whose occurrences could be reduced by good housekeeping and removal and reduction of metals in the fuel supply chain. The removal of sodium nitrite pipeline corrosion inhibitors by operators saw a significant reduction in reports of metal carboxylate IDIDs Carbonaceous deposits are the result of the degradation of diesel fuel [49-51] by the common rails high pressures, temperatures, cavitation trends in design which if anything show no sign of any reduction. The trend is more in the other direction.

Recent studies by Barker [ $[\underline{52,53}]$ confirmed by Capprotti [ $\underline{54}]$ and Feld [ $\underline{55}$ ] have shown IDIDs to be complex and multilayer in their constitution. Figure 5.

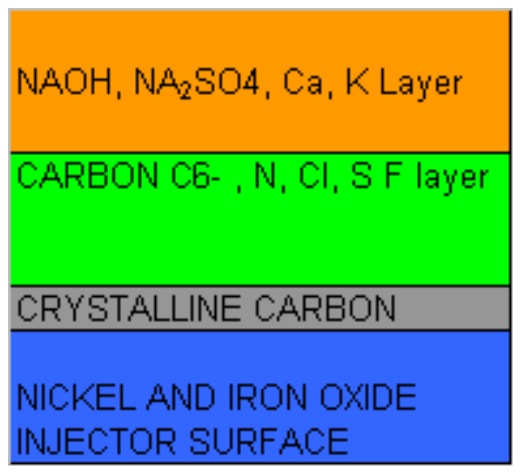

Figure 5 Schematic of depth Profile of injector deposit from ToF-SIMS

Further extension of these investigations has seen the use of Fast Ion Bombardment to cut a piece of these layered deposits from the needle and study it by other techniques such as Raman that can determine the amount of ordered and disordered carbon present. Transmission Electron Microscopy (TEM) showed graphene like structures present and Atomic Force Microscopy (AFM) showed adhesion

characteristics which are important to the retention of the next layers [56-57] of deposit.

There has also been extension of the use of the JFTOT technique by a number of groups [35 59-60] with Lacey et al correlating the deposit in the injector hardware with the deposit observed on the JFTOT tube. Bucholz [61] indicated its possible use as a preventative screen and Barker showed the wide variety of information which may be extracted from a tube deposit by modern analytical techniques [62].

Finally, another major factor in deposit formation is diesel fuel and its changing nature in recent times regarding solvency and its ability to retain deposit sources. De Goede showed [63] that with the same level of contaminants IDID build up did differ significantly when comparing a petroleum diesel reference fuel with a GTL near zero aromatic content fuel. Thus clearly the polarity and constitution of a fuel is also a fundamental parameter with regard to a fuels ability to solubilize deposit sources [므] . Since these may vary for a base mineral diesel fuel, once the wide variety of biodiesel $[26,64]$ and synthetic diesels and alternative fuels [ㄷ] $]$ are considered the picture becomes exceptionally complicated.

Page 4 of 20
Recently South East Asian countries have seen an increase in the amount of biodiesel in their fuels. The impact has been an increase in fuel filter blocking associated with monoglyceride content [6]. Other studies have shown a correlation between lowering the aromatic content fuel, a prominent increase in engine torque and a larger amount of injector deposits being formed. The effect of injector deposits on emissions, power and fuel economy performance means that studies will continue to understand the nature of these deposits, the development of new standard engine tests to mimic their production and the development of new DCA additives will continue. The latest publications have reported the following advances in knowledge. Risberg found that not only zinc neodecanoate can cause nozzle hole deposits but also sodium, calcium, copper and iron salts. A trend was also noted that the higher the charge on the metal cation the greater the fuel flow loss [25]. Sykes has used visual analysis to understand surface bound fuel in nozzles to inform on control of surface wetting and thus inhibiting nozzle coking [26]. Bernemyr has shown a correlation between low aromatic fuels and an increase in nozzle hole deposits [27]. Stepian has shown that trace metal contamination especially by zinc is a very significant factor in the initiation and acceleration of deposit formation in diesel injector systems [28]. He further showed by field test the high efficiency of modern DCAs in the mitigation of both EDIDs and IDID [29].

Gopalan has reported test rig results which indicate that any base fuel component irrespective of concentration under the high temperatures and pressures experienced in a common rail diesel injection systems will degrade promoting fuel oxidation. [30], the test used a surrogate B10 mixture. A different way of mitigation of the sodium carboxylate deposit problem has been investigated by Hallet, who used ionic liquids to extract sodium ions from a model diesel fuel. Some showing exceptional extraction capabilities of $99.1 \%$ at a concentration of $3 \mathrm{mg} \mathrm{kg}^{-1}$. [31]. Recently a review on deposit formation from biodiesel has been published, its conclusion as with many other recent works is that more work is required for a comprehensive understanding of deposit formation [64].

\section{Latest Developments}

\section{New Standard Engine Tests}

In response to the formation of IDIDs in the field the industry via the CEC has attempted to develop a further test the DW10 C test, CEC F110-16. The engine test simulates sodium carboxylate deposits by dosing the fuel with a sodium naphthenate and dodecenyl succinic acid, whilst amide deposits are simulated by dosing the fuel with a "non-commercial" low molecular weight PIBSI .The "noncommercial" low molecular weight PIBSI used had a dubious provenance as it was never established whether the material selected represented the quality of the material which resulted in field issues and therefore it's potential in protecting the market from further occurrence of the problem remained questionable, and the inability to produce reliable fouling and suitable precision for this contaminant meant a method making use of this planned reference fuel was never approved. The carboxylate version of the test has been suffering from precision issues from 2016-17. The test has been declared out of control because of the current precision from the inter-laboratory study carried out, and a pass fail criteria instead of the merit system was also not agreed upon. At present the development group at CEC is trying to identify potential sources of poor precision and tests are ongoing regarding the permitted temperatures for the soak in period. Analysis has suggested that whilst $+/-5^{\circ} \mathrm{C}$ is a small operating window its effect may be significant [20]. The test itself is being used worldwide to show the effectiveness of DCAs to combat the problem of IDIDs from both a cleanup and keep clean standpoint. However, it is being used in the 
absence of another test with no pass merit rating being widely agreed within the industry. Clean-up procedures are used but again there is no agreed procedure and the results produced are interpreted differently. There appears little appetite within the industry to continue its development and an indication from the sodium naphthenate standard supplier that they may not produce is symptomatic of this malaise. The decline in metal carboxylate deposit reports in Europe and the current political view of the diesel powertrain may also contribute. It is doubtful that this method will continue. We and others continue to use a modified DW10B test as an alternative. An overview of the CEC standard and proposed tests is shown in Table 1. Our interest in alkali carboxylates [67] has led us to look at one of the main reagents in the test and question its suitability. Herein we shall reveal some of our initial findings which will be the subject of later publications. It is important to clarify that the field problem this test is attempting to mimic is the reaction of sodium source with an acid is complex in a laboratory setting. An engine test environment will be an order of magnitude more difficult. The sodium naphthenate molecule chosen for the DW10-C engine test is problematic for a number of reasons. The main one being that it is not a single species.

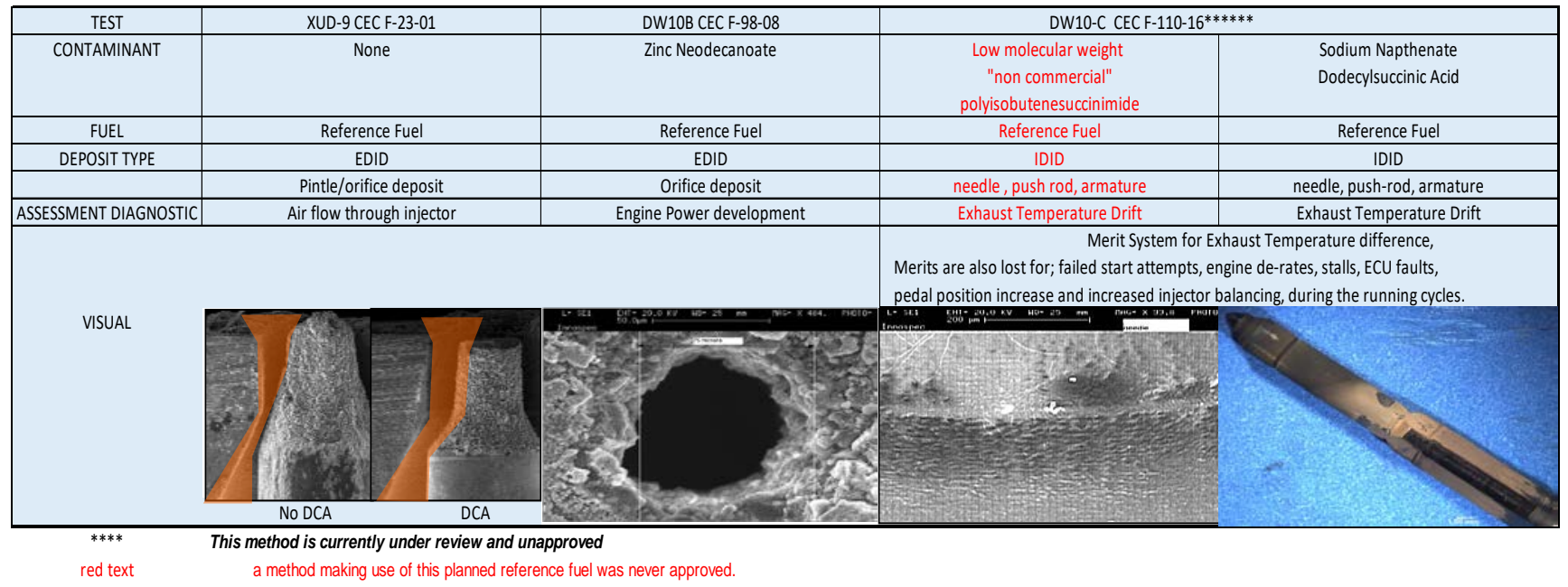

It is the sodium salt of naphthenic acid, a generic term for the mixture of cyclopentyl and cyclohexyl carboxylic acids present within crude oil. The molecular weight of such species varies from 120 up to 700 atomic mass units, with chain lengths of between 10 and 15 carbons on average [68].In a South American crude over 3000 different elemental compositions of these acid species were identified by Marshalls' group using extraction then Negative-Ion Microelectrospray High-Field Fourier Transform Ion Cyclotron Resonance Mass Spectrometry. It is clear from the literature that there is a paucity of information available on both the conclusive identity of sodium naphthenate species and indeed their parent acids. They are theorized Figure 6 , to be cyclic molecules whose generic formula is $\mathrm{C}_{n} \mathrm{H}_{2 n+\mathrm{z}} \mathrm{O}_{2}$, where $\mathrm{n}$ is the carbon number and $\mathrm{z}$ is an even, negative integer. [69] on the basis of High Pressure Liquid Chromatography Mass spectrometry.

Page 5 of 20
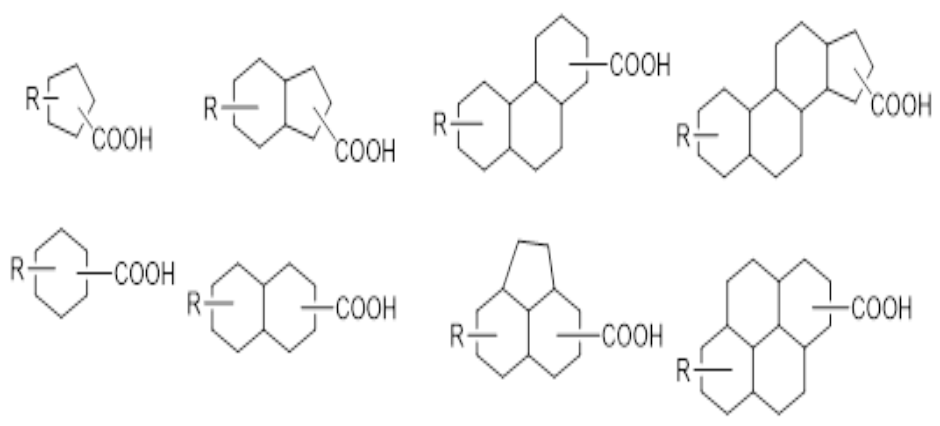

Figure 6 Selection of molecules that may be present within samples of naphthenic acid, where $\mathrm{R}$ represents an alkyl chain of indiscriminate length 
Chemical analysis has been utilised to try and provide insight into the composition of this array of molecules and their properties. This is especially important regarding the use of this material as a component of a standardised test.

\section{Solubility Studies}

Initial solubility tests of sodium naphthenate. The sodium naphthenate has to have solubility in diesel fuel to act as a sodium source. Various solvents were tried, ranging from non-polar to polar. Results are summarised in Table 2, with the polarity of the solvent increasing as the table is descended.

Table 2 Solubility of Sodium Naphthenate in various Solvents

\begin{tabular}{|c|c|}
\hline Solvent & Solubility \\
\hline Hexane & Insoluble, forms yellow gel \\
\hline Petroleum ether & Insoluble, forms a pale white gel \\
\hline Diethyl ether & Insoluble, forms a white powder \\
\hline Chloroform & $\begin{array}{llll}\begin{array}{l}\text { Soluble, forms } \\
\text { solution }\end{array} & & & \\
\text { colorless }\end{array}$ \\
\hline Dichloromethane & $\begin{array}{l}\text { Partially soluble, still some } \\
\text { powder left }\end{array}$ \\
\hline Tetrahydrofuran & Soluble, forms a yellow solution \\
\hline Acetone & Insoluble, forms a white powder \\
\hline Ethyl acetate & Insoluble, forms a white powder \\
\hline Isopropanol & $\begin{array}{l}\text { Partially soluble, forming a } \\
\text { yellow solution }\end{array}$ \\
\hline Ethanol & $\begin{array}{l}\text { Soluble, forms a pale yellow } \\
\text { solution }\end{array}$ \\
\hline Methanol & $\begin{array}{l}\text { Soluble, forms extremely pale } \\
\text { yellow solution }\end{array}$ \\
\hline Water & Soluble, forms yellow solution \\
\hline
\end{tabular}

What is apparent from this table is that there is no clear 'cut-off' point, where solvents of certain polarity dissolve the sodium naphthenate more. For example, the sodium naphthenate is soluble in chloroform and tetrahydrofuran (THF), but is insoluble in the more polar ethyl Page 6 of 20 acetate and isopropanol. The earlier use of sodium naphthenate in diesel fuel could perhaps be due to a mixture of different components of the diesel imparting different levels of polarity. Considering the variety of polarity in modern diesel fuel this complicates the ability of sodium naphthenate to act as a constant sodium source and this is before the variation from the presence and amount of water in diesel fuel is taken into consideration.

\section{Spectroscopic Studies}

The Fourier Transform Infra-red (FTIR) technique was used to identify the main functional groups present within the sodium naphthenate sample. The spectrum Figure 7 showed vibrations seen at $\sim 2900 \mathrm{~cm}^{-1}$, characteristic of aliphatic $\mathrm{CH}$ stretches, (indicating the sample is predominantly aliphatic in nature) and at 1556 and $1411 \mathrm{~cm}^{-1}$ characteristic of the asymmetric and symmetric carboxylate stretch respectively. The asymmetric stretching vibration is more intense than the symmetric stretching vibration, which can suggest a more asymmetric bonding mode in the solid state. [70].

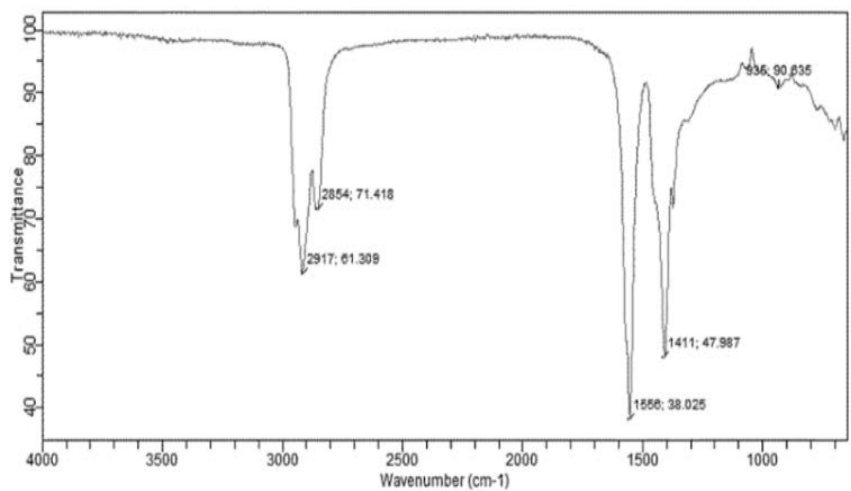

Figure 7 Infra-red Spectrum of Sodium Naphthenate

Nuclear Magnetic Resonance (NMR) spectroscopic studies were also attempted. As can be seen in Table 2, sodium naphthenate proved to be insoluble in many common solvents. Initial testing, Figure 8, looked at deuterated benzene, $\mathrm{C}_{6} \mathrm{D}_{6}$, which did provide a spectrum. This showed a series of very broad resonances between 0.89 and 2 ppm, indicative of aliphatic protons, confirming the largely aliphatic nature of the sample.

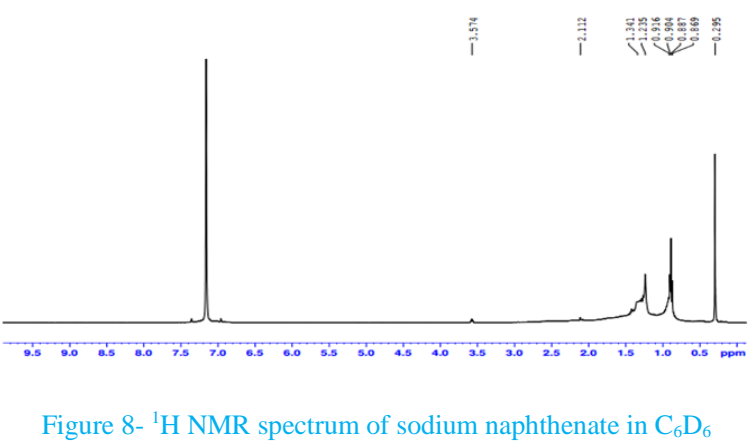

The broadness of these resonances gives some indication of the complexity of the sample, with many different species likely to be contributing to the proton environments. The experiment was then repeated, Figure 9, using deuterated tetrahydrofuran $\mathrm{d}_{8}$-THF as solvent, assuming that the increased solubility of the sodium 
naphthenate in THF would allow for an improved spectrum quality. Unfortunately this was not realized, with the resonances of the aliphatic protons in fact becoming broader and poorer quality in comparison to those seen in Figure 8. When attempting to carry out a ${ }^{13} \mathrm{C}$ spectrum in $\mathrm{d}_{8} \mathrm{THF}$, prolonged experiment scan times were necessary to see even the smallest relevant resonances such as that of the carboxylate carbon. This is difficult to explain but may be due to exchange processes on the NMR time scale.
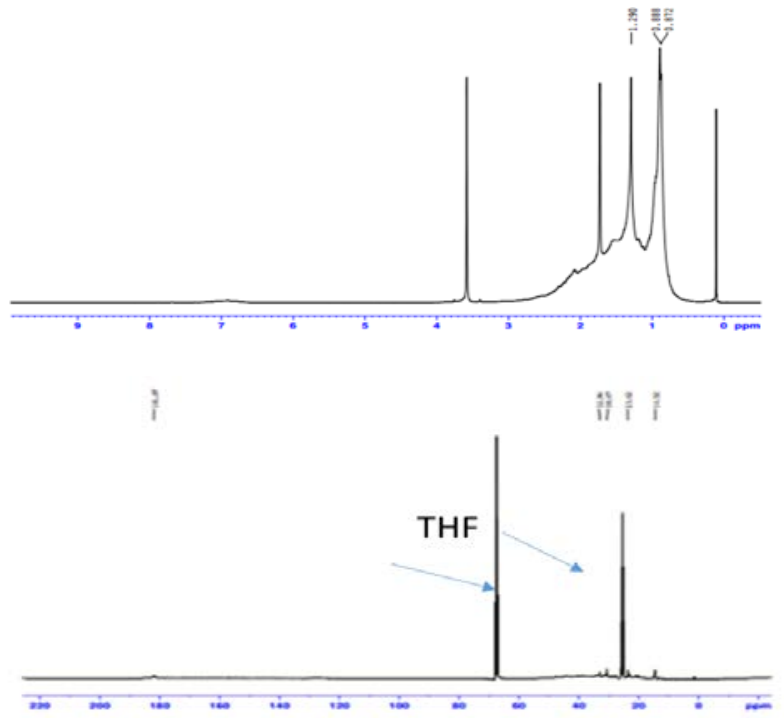

Figure 9 Top: ${ }^{1} \mathrm{H}$ NMR spectrum of sodium naphthenate in $\mathrm{d}_{8}$-THF; Bottom: ${ }^{13} \mathrm{C}$ NMR spectrum of sodium naphthenate in $\mathrm{d}_{8}$-THF (solvent resonances marked)

To attempt to gain more insight into the structure or potential structures, the sodium naphthenate was reacted with a commonly used chelating donor 1, 10-phenanthroline (1, 10-phen). The nitrogen atoms of this donor may donate to the sodium cation present in sodium naphthenate and allow for more detailed spectroscopic studies to be carried out. To this end, 1, 10-phenanthroline and sodium naphthenate were reacted together in hexane to obtain a white powder. ${ }^{1} \mathrm{H}$ NMR studies suggested coordination of the 1,10 phenanthroline to something, presumably a component of the sodium naphthenate mixture.

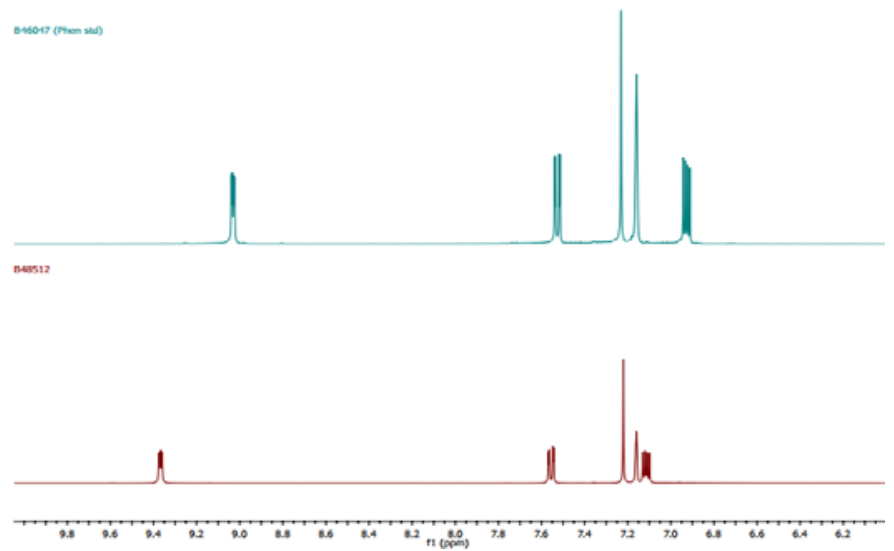

Figure 10- Comparison of ${ }^{1} \mathrm{H}$ NMR spectra showing Top: 1, 10phenanthroline and Bottom: reaction product of sodium naphthenate and 1 , 10-phenanthroline (bottom) in $\mathrm{C}_{6} \mathrm{D}_{6}$
This could be inferred by the downfield shift of the resonances associated with the 1,10-phen protons with regards to a standard Figure 10.

Diffusion Ordered Spectroscopy (DOSY NMR) was then tried. This is a technique based on the fact that molecules of different molecular weights will diffuse or rotate at different rates in solution related to their molecular weight. This fact can be exploited using calculations to allow for an estimate of the molecular weight of the species in solution, thus providing valuable insight into the structures adopted in solution. The DOSY NMR of the reaction product between 1,10phenanthroline and sodium naphthenate is shown in Figure 11.

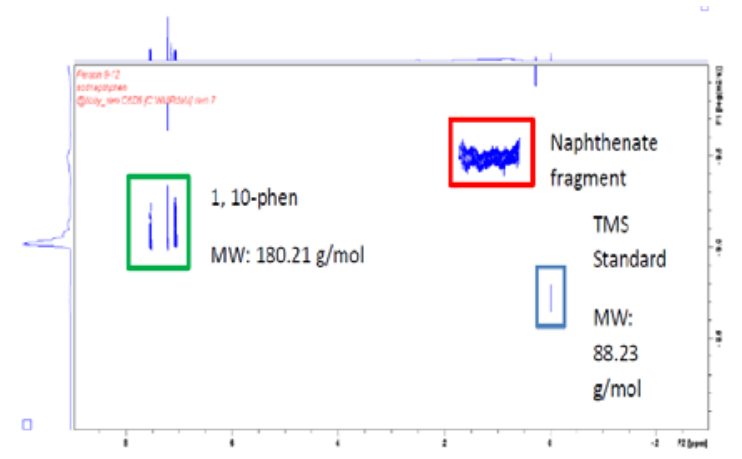

Figure 11 1H DOSY NMR spectrum of powder formed on reacting sodium naphthenate with 1, 10-phenanthroline

The diffusion coefficient, the numerical value given to each fragment of different molecular weight is calculated and then fed into software developed by Stalke et al., [71]. The diffusion coefficient for the 1 , 10 -phenanthroline fragment was calculated as $9.823 \times 10^{-10} \mathrm{~m}^{2} / \mathrm{s}$, giving a $\log$ value of $-9.0078 \mathrm{~m}^{2} / \mathrm{s}$. using the software in conjunction with the log value of the diffusion coefficient of the TMS internal standard. This predicts a molecular weight of $305 \mathrm{~g} / \mathrm{mol}$. This is too large to represent an uncoordinated free 1, 10-phenanthroline molecule, which would have a molecular weight of only180.21 $\mathrm{g} / \mathrm{mol}$. If the 1, 10-phenanthroline molecule was coordinated to a single sodium cation, the molecular weight would increase to 203 $\mathrm{g} / \mathrm{mol}$, however this gives an error of $-33 \%$, which would indicate that this is still not the species seen in solution. When the formula for 1, 10-phenanthroline coordinated to a sodium carboxylate species that may be present in sodium naphthenate, such as sodium cyclopentanoate (Figure 12), the molecular weight is calculated as $317 \mathrm{~g} / \mathrm{mol}$. This gives a much lower error of only $4 \%$, which is within the limits for the software. Therefore the DOSY data suggests that there is some sort of coordination presumably of Lewis acid Lewis base type, between 1, 10-phenanthroline and at least one component of the sodium naphthenate mixture.

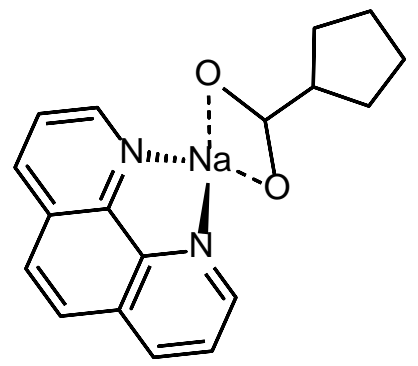

Figure 12 Proposed structure of 1, 10-phen-sodium cyclopentanoate complex suggested to be present by DOSY NMR data.

Page 7 of 20 
Attempts to obtain a more accurate insight into the structure of sodium naphthenate will be the subject of further publications.

\section{The Reaction Chemistry of Sodium Naphthenate and DDSA}

To more accurately replicate the engine testing carried out within a laboratory environment., sodium naphthenate and dodecenylsuccinic acid (DDSA) were reacted together in various ratios, ranging from and acid: sodium naphthenate ratio of 1:0.5 to 1:3. The sodium naphthenate was suspended in hexane, forming a yellow gel. DDSA was then added in the appropriate ratio and the mixture stirred overnight. The solvent was then removed, and the solid remaining analysed via ${ }^{1} \mathrm{H}$ NMR. Figure 13 compares the results of the NMR analysis for $0.5,1$ and 1.5 equivalents of sodium naphthenate.

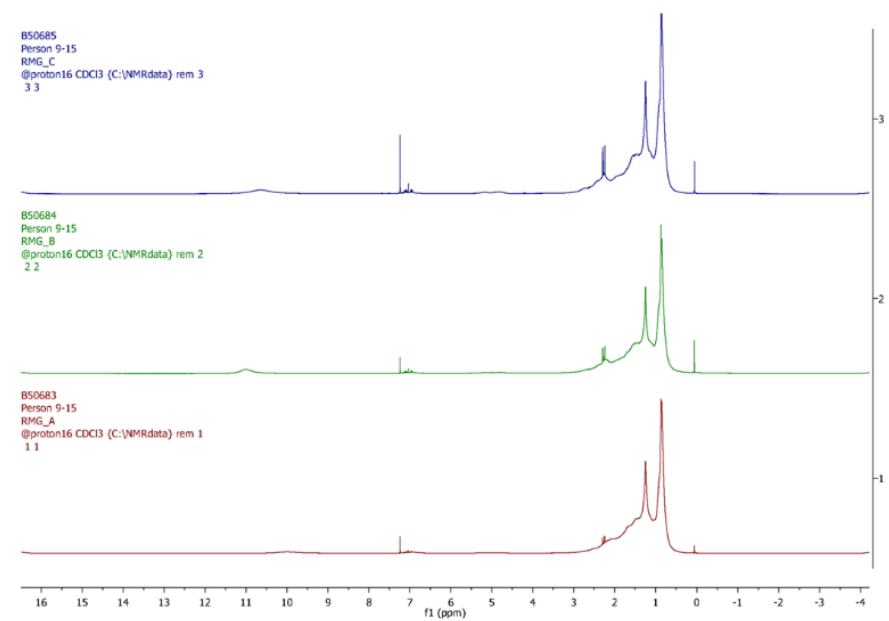

Figure 13 Comparison of ${ }^{1} \mathrm{H}$ NMR spectra showing Top: reaction product of DDSA: Na naphthenate 1:1.5; Middle; reaction product of DDSA:Na naphthenate 1:1 and Bottom: reaction product of DDSA:Na naphthenate 1:0.5

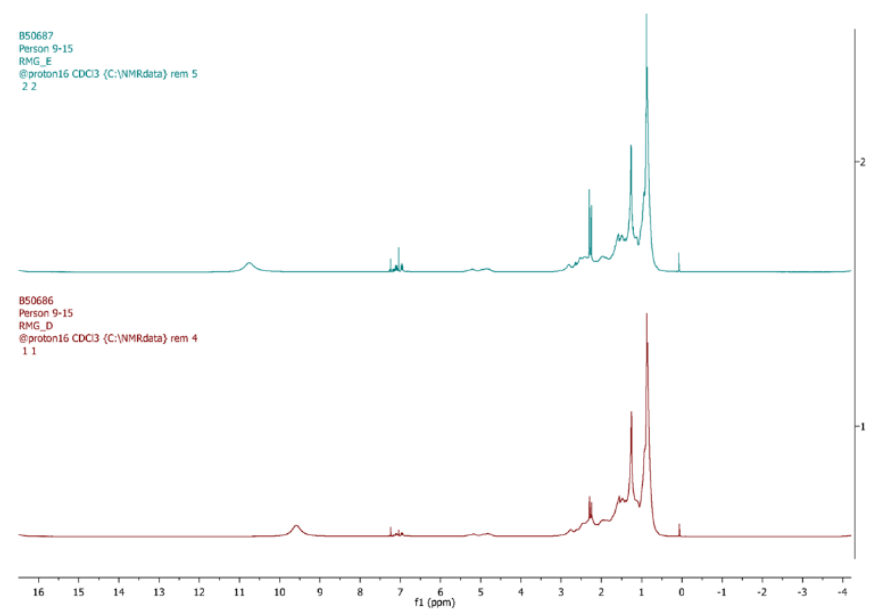

Figure 14 Comparison of ${ }^{1} \mathrm{H}$ NMR spectra showing Top: reaction product of DDSA: Na naphthenate 1:3 and Bottom: reaction product of DDSA: Na naphthenate 1:2
In all spectra, the characteristic resonance of a carboxyl proton is visible, indicating that some acid groups are still available, though the intensity is decreased at the lower sodium naphthenate ratios. The resonance is more intense in Figure 14 when compared to those seen in Figure 13, which may indicate a different acid species present in the sample. More work is required to fully understand this observation. Indeed, the major drawback of spectroscopic analysis in this instance is that it is impossible to tell if the sodium cation has transferred from the sodium naphthenate to the DDSA or the sodium cation is still bonded to the naphthenate fragment, or alternatively if a mixture has formed. Based on $\mathrm{p} K_{\mathrm{a}}$ values, it is likely that the sodium cation in these reactions remains bound to the naphthenate fragment. Both naphthenic acid and DDSA acid are likely to have similar $\mathrm{p} K_{\mathrm{a}}$ values ( $\mathrm{p} K_{\mathrm{a}}$ of DDSA approximately 5 compared to that of naphthenic acid which is likely to lie between 5 and 6 ). Therefore, due to this similarity in pKa values, there is little thermodynamic driving force for the reaction, meaning that transfer of the sodium cation from the sodium naphthenate fragment to DDSA to form a DDSA carboxylate species is unlikely to occur to any significant extent, with a constant equilibrium in place meaning it is nigh impossible to predict with any genuine certainty where the Sodium cation is in relation to any of the compounds present.

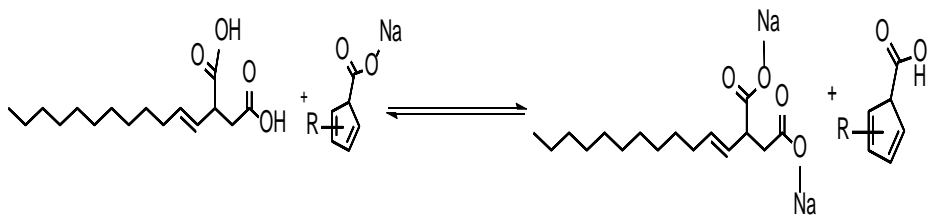

Figure 15 Equilibrium formed when DDSA and sodium naphthenate are mixed together

This is without taking into consideration the further complication of co-solvents such as 2-ethylhexanol which have been used in the DW$10 \mathrm{C}$ engine test.

\section{The Reaction of Sodium Naphthenate and DDSA in the DW10-C} Engine.

An injector needle from a DW10-C engine test has been the subject of initial analysis using Fourier Transform Infra-red Microscopy Spectroscopy (FTIRMS).

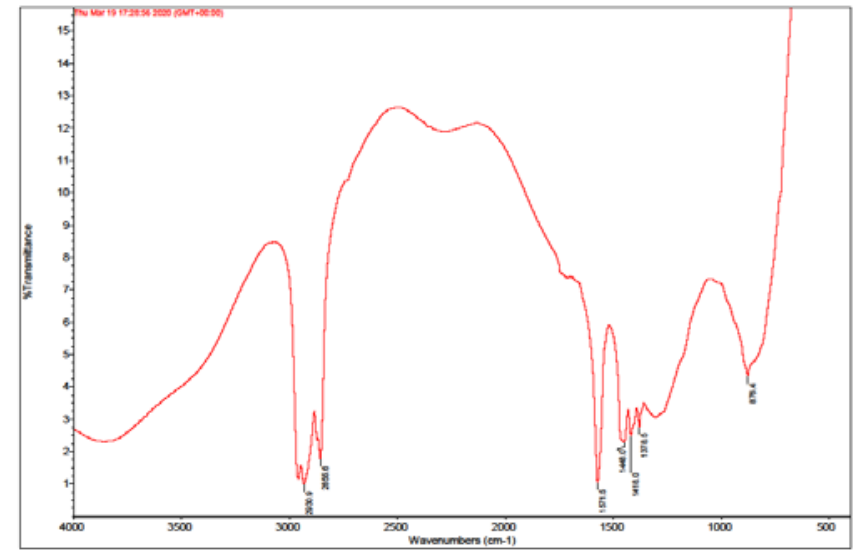

Figure 16 Microscope Infra-red spectrum of DW10-C Injector needle Tip. 


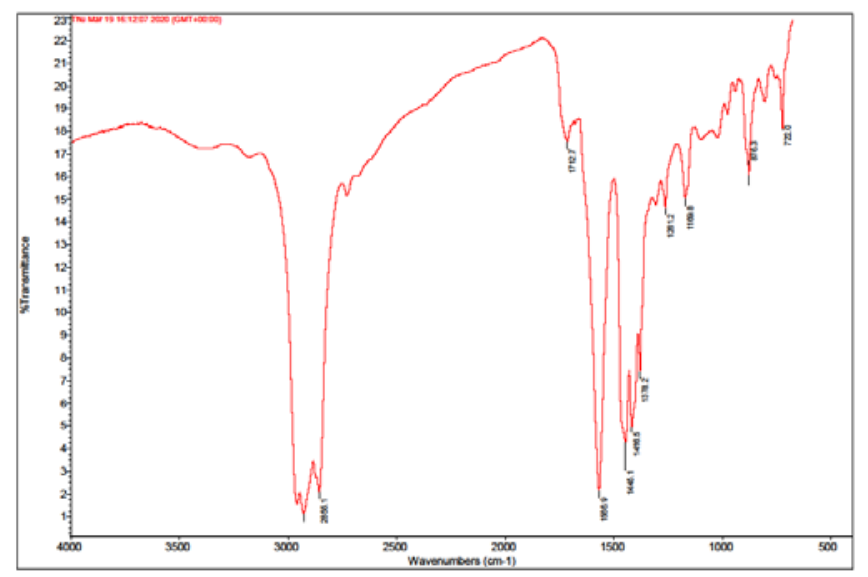

Figure 17 Microscope infra-red spectrum of injector needle near tip.

Inspection of the spectra taken at the tip and near to the tip Figures 16 and 17 of the DW10-C needle show differences as they do to the spectrum of sodium naphthenate Figure 7. These are summarized in Table 3.

Table 3 Infra-red signals of sodium naphthenate and deposits

\begin{tabular}{|r|c|c|}
\hline Sodium Naphthenate & TIP & NEAR TO TIP \\
\hline & & 1712 \\
1556 & 1572 & 1567 \\
& 1448 & 1545 \\
1412 & 1418 & 1416 \\
& 1378 & 1378 \\
\hline \multicolumn{2}{|c}{ all cm } \\
\hline
\end{tabular}

Though the differences are small they are worthy of further investigation, indicating a complex chemical reaction pathway in the engine and that the use of sodium naphthenate in a standard test which relies on a complex merit rating may not be propitious. As stated previously further work will be the subject of later publications.

\section{New Analytical Techniques}

\section{ToF-SIMS/PCA Analysis Field Samples}

The ToF-SIMS [47, 52, 54, 55, and 56] technique and Principle Component Analysis PCA methodology [62], have been described elsewhere in isolation and in combination to analyse fuel deposits. Hence a brief description follows. In ToF-SIMS a pulse of ions bombards the specimen and the energy of these primary ions is transferred to target atoms by atomic collisions. This results in a collision cascade and part of the energy is transported back to the surface enabling surface molecules and atoms to overcome surface binding energy. A cloud of molecules and atoms results some of which are ionized. The mechanism is "soft" enough to allow large non-volatile molecules with masses of up to 10,000 Daltons, with this part of the cloud showing relatively little fragmentation. The ionized particles of one polarity, atomic and molecular secondary ions, are accelerated into a Time of Flight spectrometer. The principle of the spectrometer is that the "Time of Flight "of an ion is proportional to Page 9 of 20 the square root of its mass. Thus different masses are separated during flight with the lighter ones arriving before the heavier ones. This is despite the ions all leaving the sample at the same time and being subject to the same accelerating voltage. Measuring the flight time for each ion allows the determination of its mass. The time interval between consecutive pulses is critical as the next pulse of primary ions cannot start until the primary pulse secondary ions have left the analyser. This time interval may be used for other activities such as sputtering or charge neutralization. The start time of all the secondary ions is determined using extremely short pulses having duration of less than one nanosecond. Variations in the technique allows surface analysis, imagine mapping and depth profiling of a sample. The technique was undertaken using a ToF SIMS IV Iontof GMBH. Surface Spectroscopy (static SIMS): The application of very low ion dose densities, allows quasi non-destructive surface analysis. Principle Component Analysis (PCA) [글 was then used to analyse the data. The PCA technique emphasizes variation and brings out strong patterns in a dataset. PCA is a simple non-parametric method of extracting relevant information from large data sets. It can be used to reduce complex data sets to a lower dimension thus revealing simplified structure which underlies a complex data set. In the case of ToF-SIMS, a mass list is made from each spectrum and joined together produce a combined list of masses. These are then applied to each spectrum. Using Matlab PCA tool box programme Eigenvalues were produced which give an indication to which principal component number (PCN) would yield useful data. The application of the method to eight failed needles collected across the globe would allow rapid analysis of the major ions present and inform on the worldwide similarities or lack of them. This is done in a more rapid time frame than a more conventional analysis of the large ToF-SIMS data sets. The geographic location and details of the needles are shown in Figure 18.

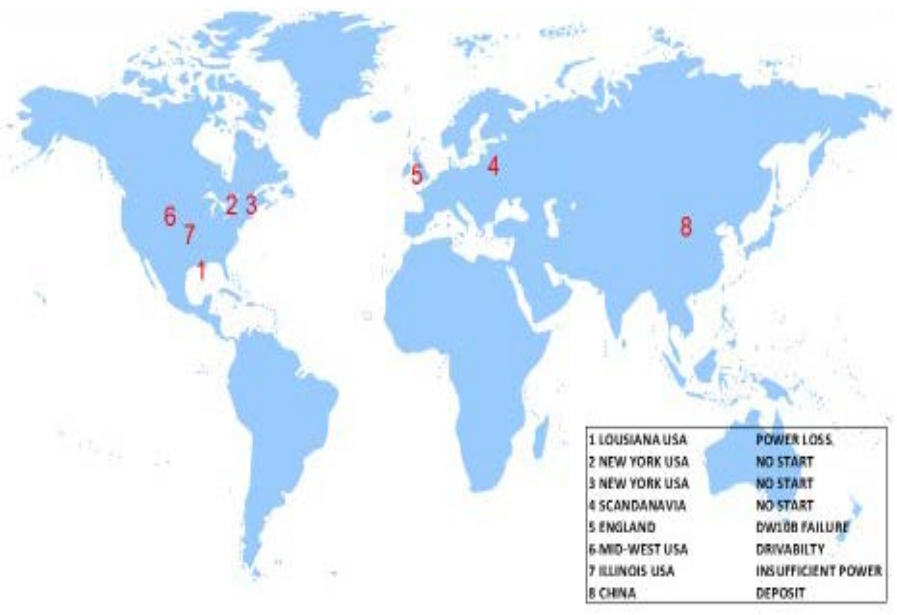

Figure 18 Location of and failure Mode of Injectors.

In the positive ion data of the eight needles, Figure 19 and Table 4. it was observed that there were differences in the ions identified, these include a variety of hydrocarbons $(\mathrm{m} / \mathrm{z} 57,41$ and 43$), \mathrm{Na}^{+}, \mathrm{K}^{+}$, $\mathrm{Na}_{2} \mathrm{OH}^{+}$and $\mathrm{SiC}_{3} \mathrm{H}_{9}{ }^{+}$, these ions were not unexpected as they have previously been reported $[35,54,59,47,73]$. Needle 3 has the most sodium on the surface, compared to the other 7 needles, this can be observed in Figure 19, and the peaks at $\mathrm{m} / \mathrm{z} 22.99$ and $\mathrm{m} / \mathrm{z} 62.98$ are at higher intensities. Polysiloxane, $\mathrm{SiC}_{3} \mathrm{H}_{9}{ }^{+}$, is found on needles 2-6. These assignments were made with SurfaceLab 6 library, with the best statistical confidence of the library and user judgement [74-76]. 


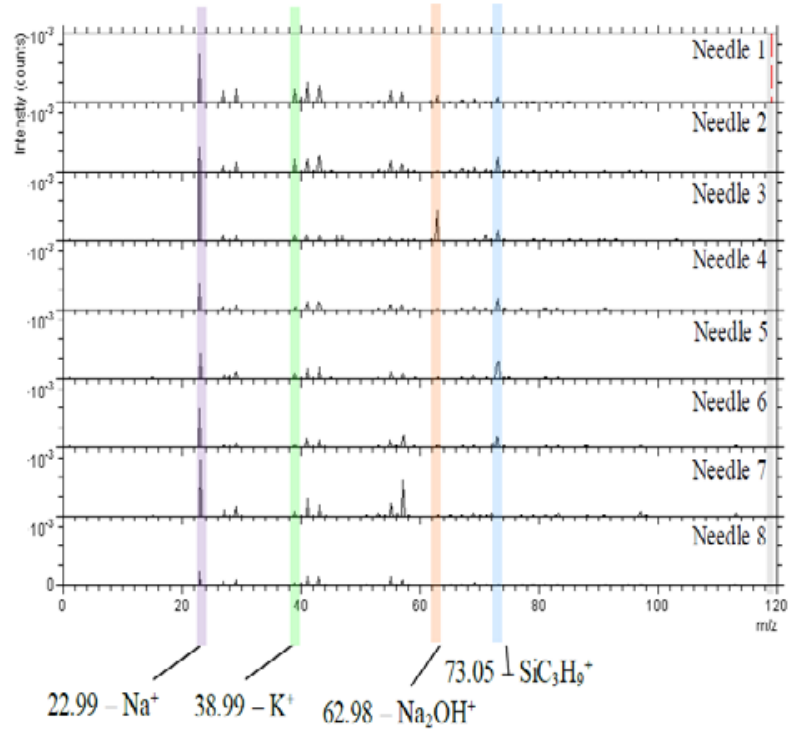

Figure 19 Positive ion surface analysis with ToF-SIMS of eight injector needles. The greatest differences have been highlighted and labelled as $\mathrm{Na}+$, $\mathrm{K}^{+}, \mathrm{Na}_{2} \mathrm{OH}^{+}$and $\mathrm{SiC}_{3} \mathrm{H}_{9}{ }^{+}$.

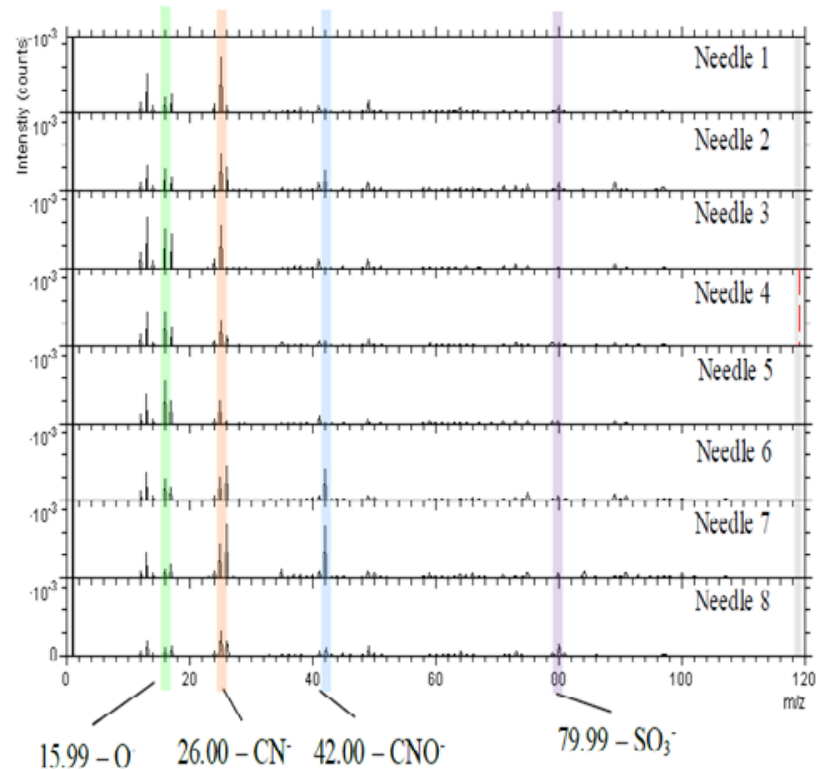

Figure 20 Negative ion surface analysis with ToF-SIMS of eight injector needles. The greatest differences have been highlighted and labelled as $\mathrm{O}^{-}$, $\mathrm{CN}^{-} \mathrm{CNO}^{-}$and $\mathrm{SO}_{3}^{-}$.

In the negative ion spectra it was again Figure 20 observed that there were differences in the ions, which included nitrogen containing species $\mathrm{CN}^{-}$and $\mathrm{CNO}^{-}$, carbon and oxygen species such as $\mathrm{O}^{-}, \mathrm{C}^{-}$, $\mathrm{CH}^{-}, \mathrm{OH}^{-}$as well as sulphate and phosphate species. The nitrogen containing peaks at $\mathrm{m} / \mathrm{z} 26.00$ and $\mathrm{m} / \mathrm{z} 42.00$ were found on needles 1 , 2, 4, 6-8, whilst oxygen ions, $\mathrm{O}^{-}$, and sulphate ions, $\mathrm{SO}^{\mathrm{x}}$, were found on all of the needles in varying intensities. Nitrogen, sulphur and phosphorus containing species regularly occur in IDIDs and are suspected to be indicative of lube oil residues.

Page 10 of 20
To enable a PCA analysis of each needle data were collected at a further two points on each needle totalling three points from each of the eight needles, $2 \mathrm{~mm}$ apart. The analysis points were then collected in four regions of interest, creating twelve data points for each needle. The data set was so large that manual analysis of the data would be arduous. Therefore principle component analysis (PCA) was applied to aid analysis of the data. PCA gives statistical evidence showing differences and similarities in large data sets, which is advantageous with large data sets and requires more substantial evidence of a variance. The principal component (PC) number indicates the severity of the difference. For ToF-SIMS this method is valuable to examine all ions and observe differences. Only PC 1 and PC 2 have been reported due to no trend occurring from the PC 3 data.

\section{Positive Ion PC 1}

The positive ion data is shown in Table 4, Figures 19, 21 and 22. In Figure 21i the data for PC 1 and PC 2 are shown. The data shows that on PC 1 there is an outlying sample set, which is needle 3, and this was visually observed in the spectra in Figure 19. It can be observed from Figure 21ii that the ions responsible for the difference were $\mathrm{Na}^{+}$ and $\mathrm{Na}_{2} \mathrm{OH}^{+}$. The negative loading on PC 1 was identified to be a range of hydrocarbons.

Table 4 PCA of positive ion data of ToF-SIMS, with the positive and negative loadings and the assignment for each ion for PC1and PC 2.

\begin{tabular}{|c|c|c|c|c|c|}
\hline PC 1 & & & $\mathrm{C} 2$ & & \\
\hline Mass & $\begin{array}{l}\text { Positive } \\
\text { Loading }\end{array}$ & Assignment & Mass & $\begin{array}{l}\text { Positive } \\
\text { Loading }\end{array}$ & Assignment \\
\hline 22.99 & $9.21 \mathrm{E}-01$ & $\mathrm{Na}^{+}$ & 73.07 & $7.07 \mathrm{E}-01$ & $\mathrm{SiC}_{3} \mathrm{H}_{9}+$ \\
\hline 62.99 & $2.32 \mathrm{E}-01$ & $\mathrm{Na}_{2} \mathrm{OH}^{+}$ & 147.10 & $1.98 \mathrm{E}-01$ & $\mathrm{Si}_{2} \mathrm{C}_{6} \mathrm{H}_{19}{ }^{+}$ \\
\hline 70.99 & $3.96 \mathrm{E}-02$ & $\mathrm{C}_{5} \mathrm{H}_{11}{ }^{+}$ & 59.04 & $4.48 \mathrm{E}-02$ & $\mathrm{C}_{4} \mathrm{H}_{11}{ }^{+}$ \\
\hline 45.98 & $3.36 \mathrm{E}-02$ & $\mathrm{Na}_{2}^{+}$ & 27.97 & $4.38 \mathrm{E}-02$ & $\mathrm{Si}^{+}$ \\
\hline 46.99 & $2.92 \mathrm{E}-02$ & $\mathrm{Na}_{2} \mathrm{H}^{+}$ & 207.06 & $4.14 \mathrm{E}-02$ & $\mathrm{Si}_{3} \mathrm{C}_{5} \mathrm{H}_{15} \mathrm{O}_{3}{ }^{+}$ \\
\hline 117.02 & $2.53 \mathrm{E}-02$ & $\mathrm{C}_{9} \mathrm{H}_{9}{ }^{+}$ & 221.15 & $3.59 \mathrm{E}-02$ & $\mathrm{Siz}_{3} \mathrm{C}_{7} \mathrm{H}_{21} \mathrm{O}_{4}{ }^{+}$ \\
\hline 128.96 & $2.51 \mathrm{IE}-02$ & $\mathrm{C}_{10} \mathrm{H}_{8}^{+}$ & 38.96 & $3.58 \mathrm{E}-02$ & $\mathrm{~K}^{+}$ \\
\hline Mass & $\begin{array}{r}\text { Negative } \\
\text { Loading }\end{array}$ & Iment & Mass & $\begin{array}{r}\text { Negative } \\
\text { Loading }\end{array}$ & nment \\
\hline 29.04 & $-2.34 \mathrm{E}-02$ & $\mathrm{C}_{2} \mathrm{H}_{5}{ }^{+}$ & 113.14 & $-7.33 \mathrm{E}-02$ & $\mathrm{C}_{8} \mathrm{H}_{17}{ }^{+}$ \\
\hline 83.09 & $-2.42 \mathrm{E}-02$ & $\mathrm{C}_{6} \mathrm{H}_{11^{+}}$ & 83.09 & $-7.61 \mathrm{E}-02$ & $\mathrm{C}_{6} \mathrm{H}_{11}{ }^{+}$ \\
\hline 147.10 & $-2.44 \mathrm{E}-02$ & $\mathrm{Sin}_{2} \mathrm{C}_{6} \mathrm{H}_{19^{+}}$ & 56.06 & $-8.53 \mathrm{E}-02$ & $\mathrm{C}_{4} \mathrm{H}_{8}{ }^{+}$ \\
\hline 69.07 & $-4.11 \mathrm{E}-02$ & $\mathrm{C}_{5} \mathrm{H}_{9}{ }^{+}$ & 27.02 & $-9.22 \mathrm{E}-02$ & $\mathrm{C}_{2} \mathrm{H}_{3}{ }^{+}$ \\
\hline 41.04 & $-6.20 \mathrm{E}-02$ & $\mathrm{C}_{4} \mathrm{H}_{5}+$ & 43.05 & $-9.24 \mathrm{E}-02$ & $\mathrm{C}_{3} \mathrm{H}_{7}^{+}$ \\
\hline 73.06 & $-6.33 \mathrm{E}-02$ & $\mathrm{SiC}_{3} \mathrm{H}_{9}^{+}$ & 97.11 & $-1.10 \mathrm{E}-01$ & $\mathrm{C}_{7} \mathrm{H}_{13}{ }^{+}$ \\
\hline 43.06 & $-7.63 \mathrm{E}-02$ & $\mathrm{C}_{3} \mathrm{H}_{7}^{+}$ & 29.04 & $-1.36 \mathrm{E}-01$ & $\mathrm{C}_{2} \mathrm{H}_{5}^{+}$ \\
\hline 57.07 & $-8.26 \mathrm{E}-02$ & $\mathrm{C}_{4} \mathrm{H}_{9}{ }^{+}$ & 55.04 & $-1.76 \mathrm{E}-01$ & $\mathrm{C}_{4} \mathrm{H}_{7}{ }^{+}$ \\
\hline 55.05 & $-8.35 \mathrm{E}-02$ & $\mathrm{C}_{4} \mathrm{H}_{7}^{+}$ & 41.04 & $-2.62 \mathrm{E}-01$ & $\mathrm{C}_{3} \mathrm{H}_{5}^{+}$ \\
\hline & & & 57.07 & $-4.67 \mathrm{E}-01$ & $\mathrm{C}_{4} \mathrm{H}_{9}{ }^{+}$ \\
\hline
\end{tabular}


i)

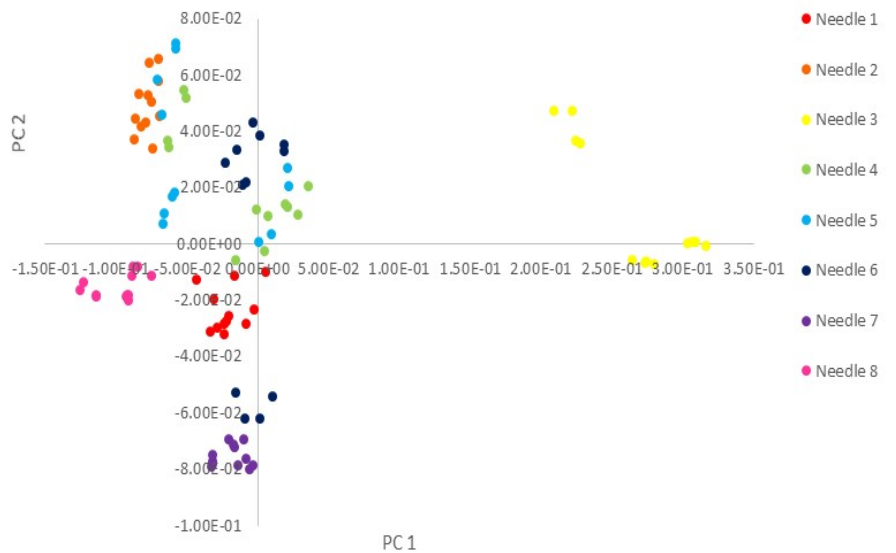

ii)

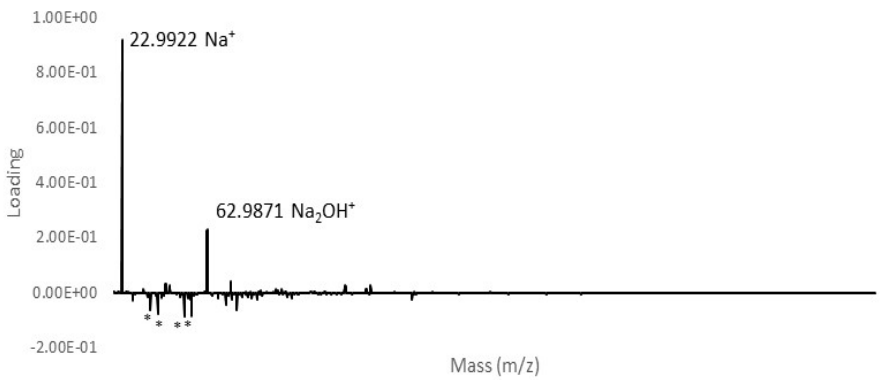

iii)

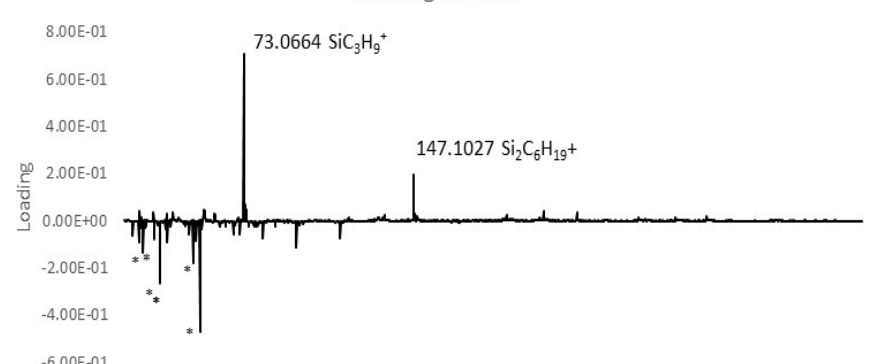

$-6.00 E-01$

$\operatorname{Mass}(\mathrm{m} / \mathrm{z})$

*- Hydrocarbon

Figure 21 Principal Component Analysis of positive ion data. i) Scores of PC 1 against PC 2 ii) Loading on PC 1, indicating the main ions iii) Loading on PC 2, indicating the main ions.
$\mathrm{Na}^{+}$
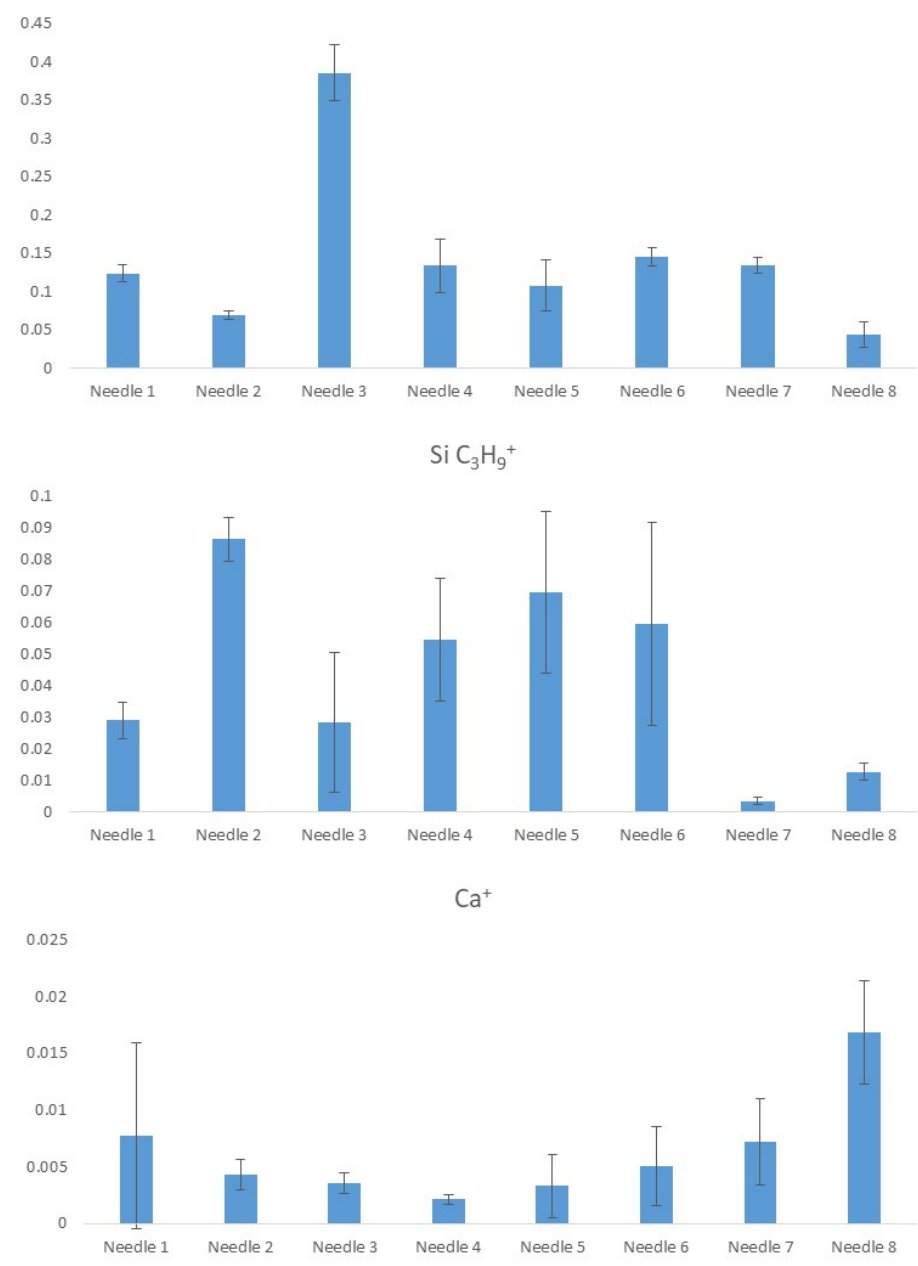

$-0.005$

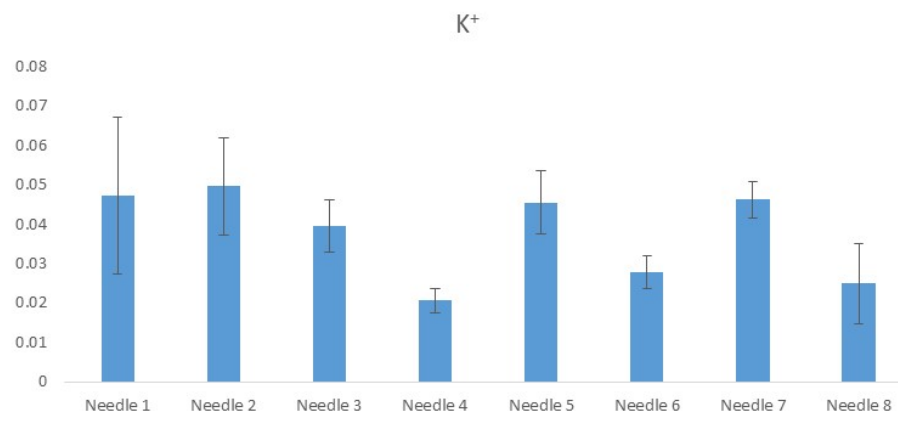

Figure 22. Bar Charts of Ions Observed Against Intensity.

Positive Ion PC 2

In Figure 23i the data for positive ions for PC 2 can be observed, although there is no visual split, as with PC 1 , it can be seen that needles 2, 3, 4, 5 and partially 6 are positive for PC 2, whereas needles 7 and 8 are negative. Figure 23iii shows that for PC 2 the positive loading was identified as polysiloxanes $\mathrm{SiC}_{3} \mathrm{H}_{9}{ }^{+}$and $\mathrm{Si}_{2} \mathrm{C}_{6} \mathrm{H}_{19}{ }^{+}[\underline{74-76}]$, and the negative loading was from hydrocarbons, $n-\mathrm{C}_{4} \mathrm{H}_{\mathrm{y}}$ and $\mathrm{n}-\mathrm{C}_{5} \mathrm{H}_{\mathrm{y}}$. Needles $1,2,7$ and 8 have tight groupings, which is supportive of repeatability of the data and a uniformity of the deposits. The differences are shown graphically in Figure 24. 
On analysis of needles 3, 4, 5 and 6 there was a chemical difference along the length of the needle which is seen as the data points splitting. This is suspected to be due to the stability of the chemistry of the fuel as it sees different environments along the needle. The other ions observed for PC 2 depicted in Figure 21iii, that are indicating a high or low loading have been identified and assigned in Table 5. A range of ions were detected with varying masses up to $\mathrm{m} / \mathrm{z}$ 221.15, which is suspected to be a polysiloxane [4-76]. The differences are shown graphically in Figure 21.

\section{Negative Ion PC 1}

The findings of the negative ion PCA data are depicted in Table 5 Figure 23 and 24, the graph shows the data for PC 1 and PC 2. For the PC 1 data it was observed that needles 6 and 7 are a positive score and the ions identified for this are $\mathrm{CN}^{-}$and $\mathrm{CNO}^{-}$, shown in Figure 23ii. Needles 3, 4 and 5 have a negative score and this is due to a greater intensity of $\mathrm{PO}^{\mathrm{x}-}$ and $\mathrm{SO}^{\mathrm{x}-}$ ions. Needles 1,2 and 8 were clustered around zero loading for PC 1 , which means that the ions are present on the needles but are not in high intensities compared to that on the other needles.

\section{Negative Ion PC 2}

The negative ion data for PC 2 is depicted in Figure 23iii. Needle 3, 6 and 7 are positive had a positive score for PC 2. The positive loading for PC 2 was due to oxygen and nitrogen species, including $\mathrm{O}^{-}, \mathrm{OH}^{-}$, $\mathrm{CN}^{-}$and $\mathrm{CNO}^{-}$. Needles 2 and 8 had a negative score for PC 2. The negative loading on PC 2 identified that sulphates and phosphates were the main ion intensity difference, the ion identified were SO3$\mathrm{PO}^{-}$and sulphate and phosphate groups attached to hydrocarbon chains. For needles 1, 4 and 5 there were analysis points with positive and negative scores, the points split, therefore showing that there were different chemistries along the needle and that both ions that were assigned for positive and negative scoring were found on these needles.

Table 5 PCA of Negative ion data of ToF-SIMS, with the positive and negative loadings and the assignment for each ion for PC1and PC

\begin{tabular}{|c|c|c|c|c|c|}
\hline PC1 & & & PC2 & & \\
\hline Mass & $\begin{array}{l}\text { Positive } \\
\text { Loading }\end{array}$ & Assignment & Mass & $\begin{array}{l}\text { Positive } \\
\text { Loading }\end{array}$ & Assignment \\
\hline 42.00 & $5.97 \mathrm{E}-01$ & $\mathrm{CNO}^{-}$ & 13.01 & $5.58 \mathrm{E}-01$ & $\mathrm{CH}^{-}$ \\
\hline 13.01 & $5.28 \mathrm{E}-01$ & CH- & 42.00 & 4.08E-01 & $\mathrm{CNO}^{-}$ \\
\hline 26.00 & $5.28 \mathrm{E}-01$ & $\mathrm{CN}^{*}$ & 25.01 & $3.21 \mathrm{E}-01$ & $\mathrm{C}_{2} \mathrm{H}^{-}$ \\
\hline 91.00 & 7.39E-02 & $\mathrm{C}_{7} \mathrm{H}_{7}^{*}$ & 15.99 & $2.86 \mathrm{E}-01$ & $\mathrm{O}^{-}$ \\
\hline 79.96 & $7.07 \mathrm{E}-02$ & $\mathrm{SO}_{3}{ }^{-}$ & 17.00 & $2.15 \mathrm{E}-01$ & $\mathrm{OH}^{-}$ \\
\hline 50.00 & 6.91E-02 & $\mathrm{C}_{4} \mathrm{H}_{2}{ }^{-}$ & 26.00 & $1.87 \mathrm{E}-01$ & $\mathrm{CN}^{-}$ \\
\hline 66.00 & $6.76 \mathrm{E}-02$ & $\mathrm{C}_{3} \mathrm{NO}^{-}$ & 12.00 & $1.82 \mathrm{E}-01$ & $\mathrm{C}^{*}$ \\
\hline 83.97 & $5.54 \mathrm{E}-02$ & $\mathrm{SiC}_{3} \mathrm{H}_{4} \mathrm{O}^{-}$ & 24.00 & $1.06 \mathrm{E}-01$ & $\mathrm{C}_{2}{ }^{-}$ \\
\hline \multirow[t]{4}{*}{75.00} & $5.21 \mathrm{E}-02$ & $\mathrm{SiC}_{2} \mathrm{H}_{7} \mathrm{O}^{-}$ & 75.00 & 7.72E-02 & $\mathrm{SiC}_{2} \mathrm{H}_{7} \mathrm{O}^{-}$ \\
\hline & & & 91.00 & $7.55 \mathrm{E}-02$ & $\mathrm{C}_{7} \mathrm{H}_{7}^{-}$ \\
\hline & & & 65.01 & $5.33 \mathrm{E}-02$ & $\mathrm{C}_{4} \mathrm{HO}^{-}$ \\
\hline & & & 83.97 & $4.58 \mathrm{E}-02$ & $\mathrm{SiC}_{3} \mathrm{H}_{4} \mathrm{O}^{-}$ \\
\hline \multirow[t]{2}{*}{ Mass } & Negative & Assignment & Mass & Negative & Assignment \\
\hline & Loading & & & Loading & \\
\hline 25.01 & $-7.81 \mathrm{E}-02$ & $\mathrm{C}_{2} \mathrm{H}^{-}$ & 299.16 & $-2.59 \mathrm{E}-04$ & $\mathrm{C}_{1} 5 \mathrm{H}_{25} \mathrm{PO}_{4}{ }^{-}$ \\
\hline 12.00 & $-9.99 \mathrm{E}-02$ & $\mathrm{C}^{-}$ & 344.97 & $-2.79 \mathrm{E}-04$ & $\mathrm{C}_{19} \mathrm{H}_{22} \mathrm{PO}_{4}^{-}$ \\
\hline 17.00 & $-2.15 \mathrm{E}-01$ & $\mathrm{OH}^{-}$ & 325.30 & $-4.01 \mathrm{E}-02$ & $\mathrm{C}_{18} \mathrm{H}_{29} \mathrm{SO}_{3}$ \\
\hline 13.01 & $-3.03 \mathrm{E}-01$ & $\mathrm{CH}^{-}$ & 311.35 & $-4.57 \mathrm{E}-02$ & $\mathrm{C}_{1}, \mathrm{H}_{2} 7 \mathrm{SO}_{3}{ }^{-}$ \\
\hline \multirow[t]{6}{*}{15.99} & $-3.58 \mathrm{E}-01$ & $\mathrm{O}^{-}$ & 79.03 & $-5.96 \mathrm{E}-02$ & $\mathrm{PO}_{3}{ }^{-}$ \\
\hline & & & 64.00 & $-6.19 \mathrm{E}-02$ & $\mathrm{SO}_{2}^{*}$ \\
\hline & & & 97.02 & $-6.59 \mathrm{E}-02$ & $\mathrm{C}_{8} \mathrm{H}^{-}$ \\
\hline & & & 73.01 & $-8.47 \mathrm{E}-02$ & $\mathrm{C}_{6} \mathrm{H}^{-}$ \\
\hline & & & 79.96 & $-1.06 \mathrm{E}-01$ & $\mathrm{SO}_{3}{ }^{-}$ \\
\hline & & & 183.02 & $-1.27 \mathrm{E}-01$ & $\mathrm{C}_{8} \mathrm{H}_{7} \mathrm{SO}_{3}{ }^{*}$ \\
\hline
\end{tabular}

Page 12 of 20 i) Negative Data $-P C 1$ against PC 2

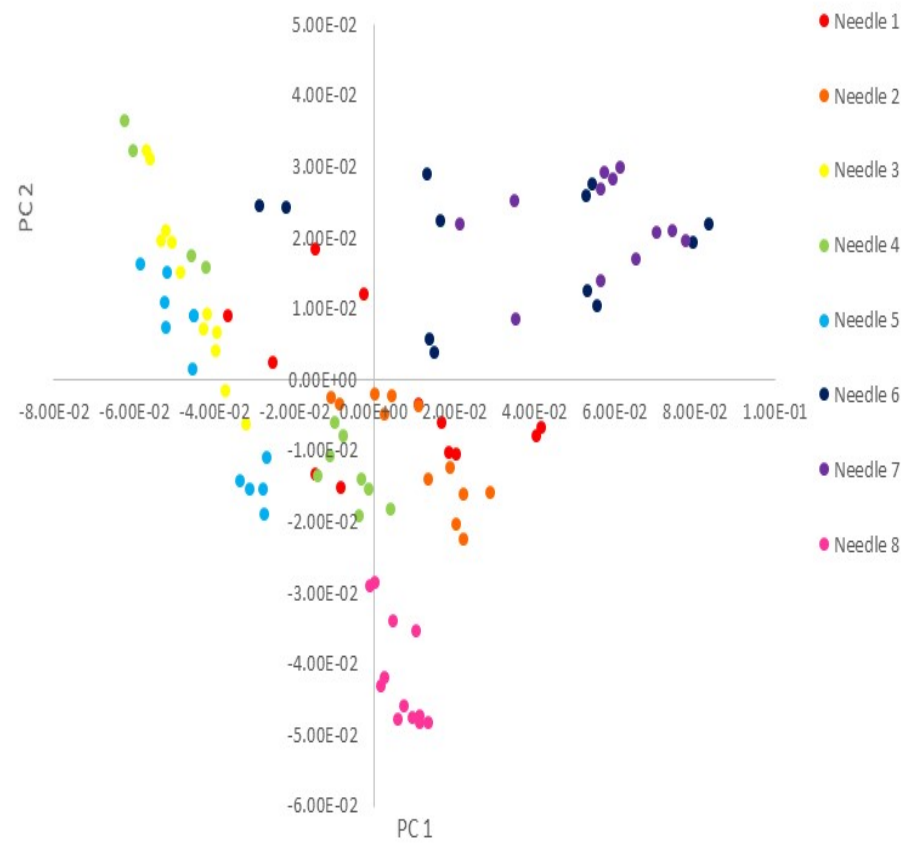

ii) Loading on PC 1

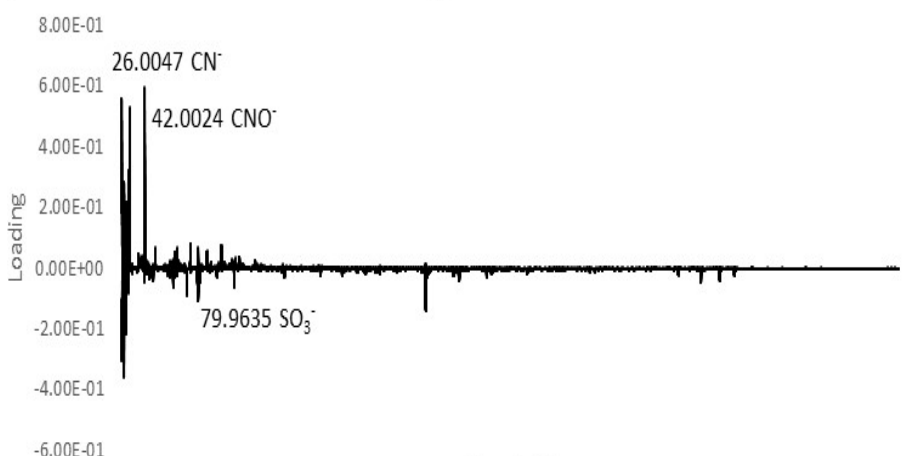

Mass $(\mathrm{m} / \mathrm{z})$

iii)

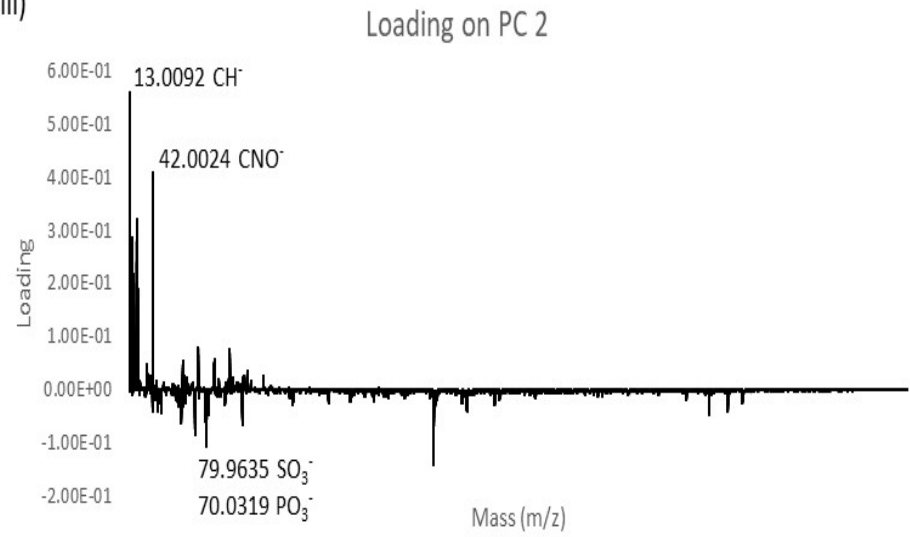

Figure 23 Principal component analysis of negative ion data. i) Scores of PC 1 against PC 2 ii) Loading on PC 1, indicating the main ions iii) Loading on PC 2 , indicating the main ions. 
$\mathrm{CN}-$

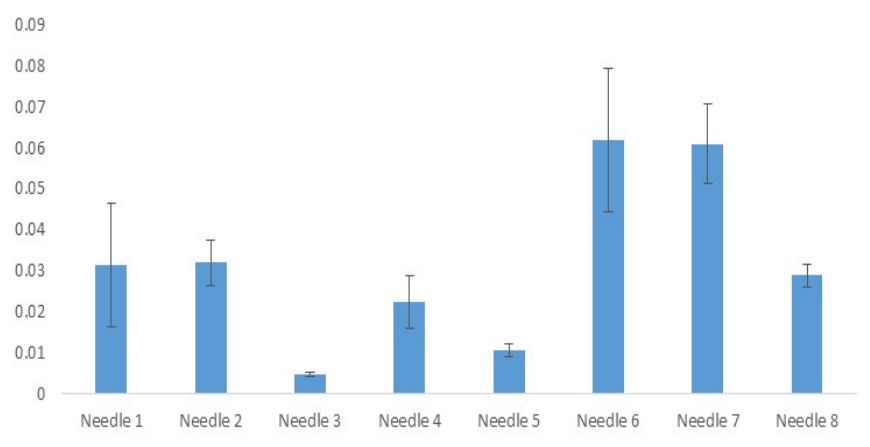

CNO-

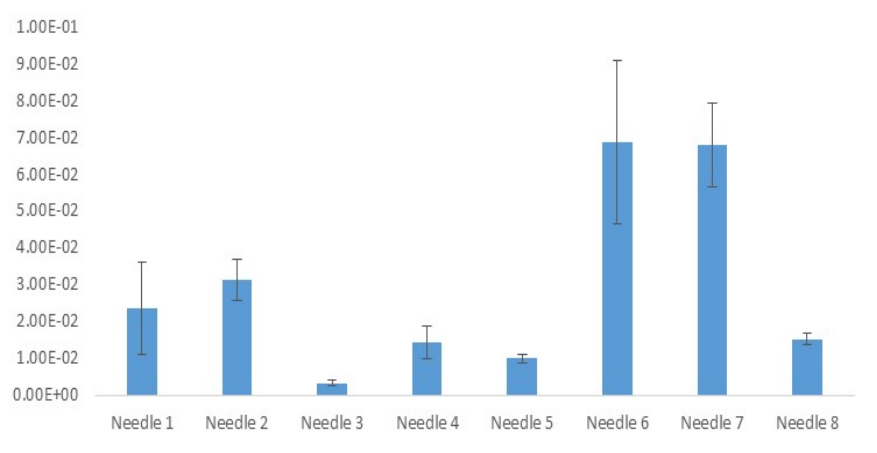

Sum of POX-

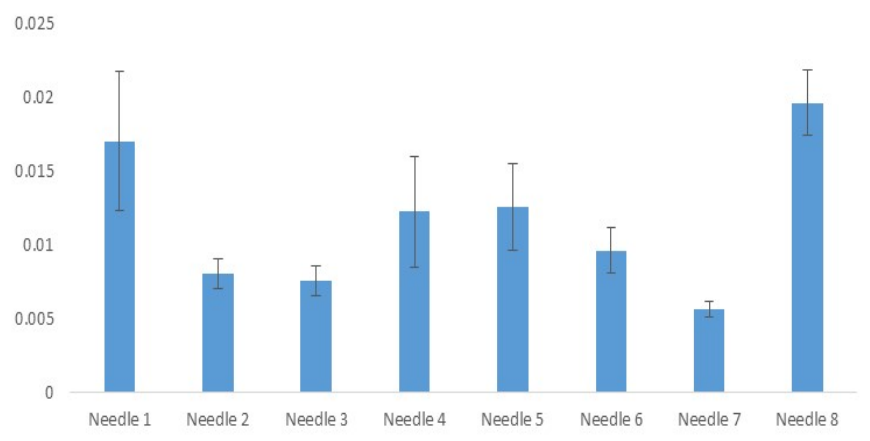

Sum of SOx-

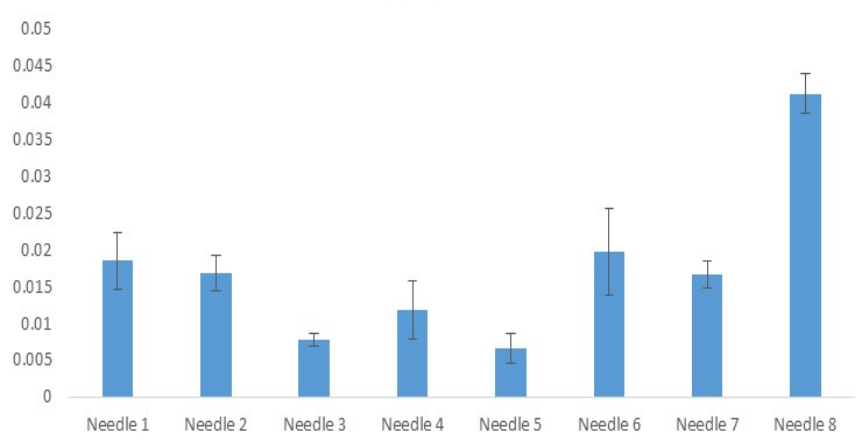

Figure 24. Bar charts of Ions Observed against Intensity.
Examination of PCA of Eight Injector Needles

The purpose of this investigation was to identify similarities and differences in the chemistries of the eight needles that were analysed. This is an initial study to show the merits of the technique. Further work with more prescriptive sample sets could be envisaged. Needle 3 has the greatest difference, with regards to the sodium levels detected and phosphate and sulphate groups, with no other needles scoring similarly to needle 3 . Needles 6 and 7 scored comparably for the positive ion data and had similar negative data except for the split of the needle 7 points on PC 2 . There was also a similarity observed for needles 2 and 8, both scoring negatively for PC 1 with the positive ion data which was an increased intensity for hydrocarbons and a lower sodium count. Both needles also had a negative score for PC 2 with the negative ion data which was assigned to be phosphate and sulphate groups. This was not to be expected as needle 2 was a DW10B engine test and needle 8 was from China and as such both have different fuel specifications and one was a standard engine test. There was also a similarity seen in the data observed for needles 1 and 4 , since needle 1 was from Scandinavia and needle 4 was from Illinois USA, therefore again a similarity was not expected, levels of the sodium species and hydrocarbons were not in high intensities on these needles. The data shows that there was more phosphate and sulphate groups on needle 1 and more nitrogen containing species on needle 4 .

To conclude, PCA has been successfully used to analyse the ions from eight injector needles and has rapidly identified similarities and differences in chemistries world-wide.

However, the limiting factor is this was surface analysis and further differences in layer chemistry attributable to failures may lie under the surface, therefore the 3D structure analysis is the only technique to fully describe the nature of the deposits.

\section{FIB-ToF-SIMS of EDID.}

This technique is a development of the Focused Ion Beam (FIB) lift out technique described by Barker et al [ㅌ6] to provide a multi-layer sample for ToF-SIMS analysis and other analysis. Normally the FIB cutting and sample mounting is fraught with difficulty because of the fragile nature of the deposit and the necessary transportation between instruments. In this case the instrument allows both the sample preparation and the analysis to be carried out on the same instrument. Figure 25. The sample used was the injector tip associated with needle 4 and the details can be found in Figure 18. The trench was milled to expose the lower chemical composition, observed in Figure 27. From the SEM image a horizontal crack in the deposit was seen. It was here that there was a chemical division perceived with ToFSIMS analysis. 

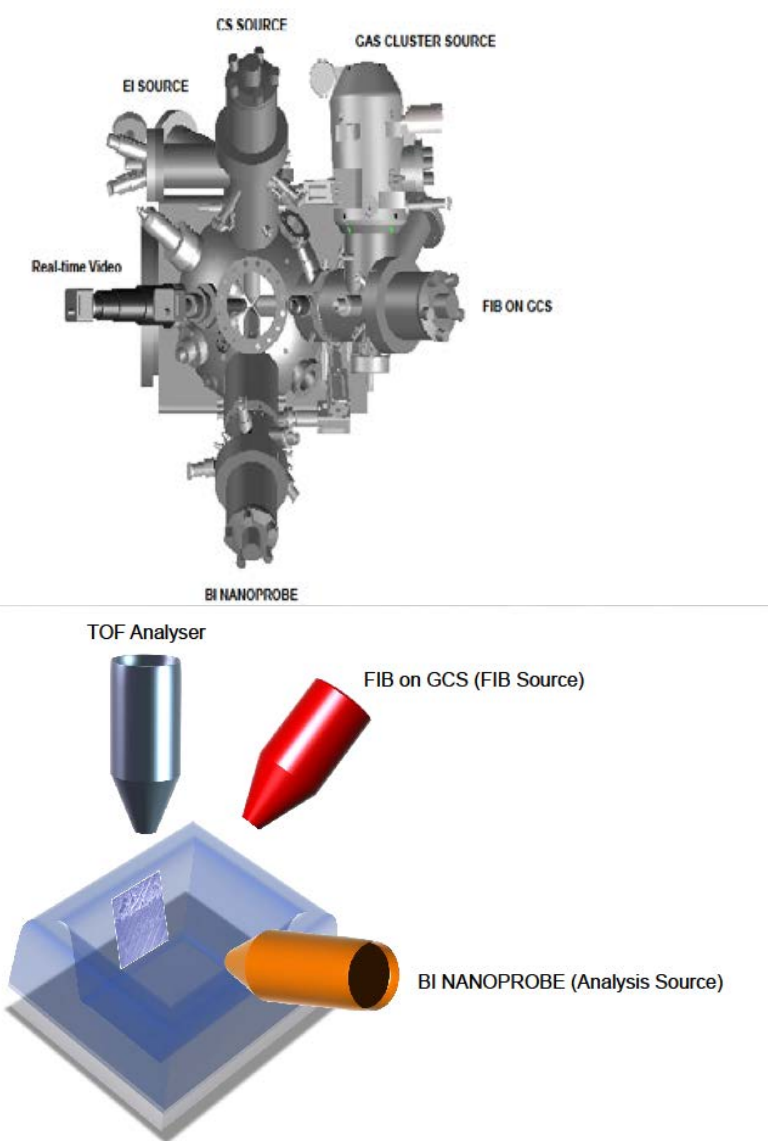

Figure 25 FIB-ToF-SIMS (ION-TOF GmbH)

The sample was from a no start medium duty vehicle from Scandinavia Figure 25 In this case the EDID on the outside of the nozzle was investigated rather than the IDID. This was because no investigation of possible layering in EDID had to our knowledge been carried out.

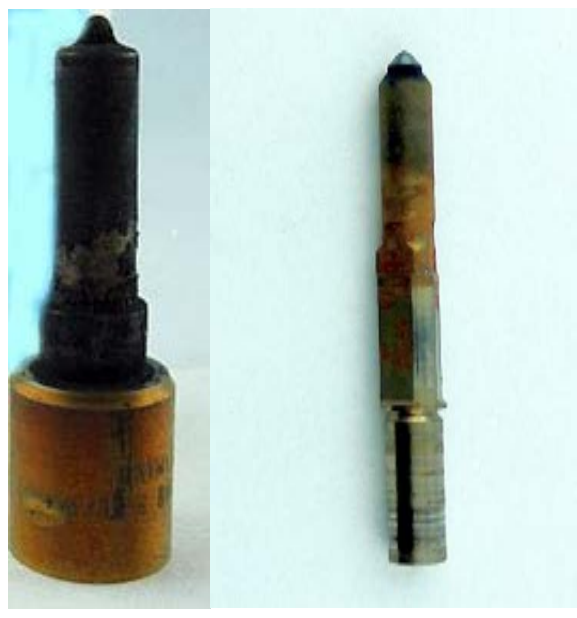

Figure 26 Scandinavian nozzle and needle.

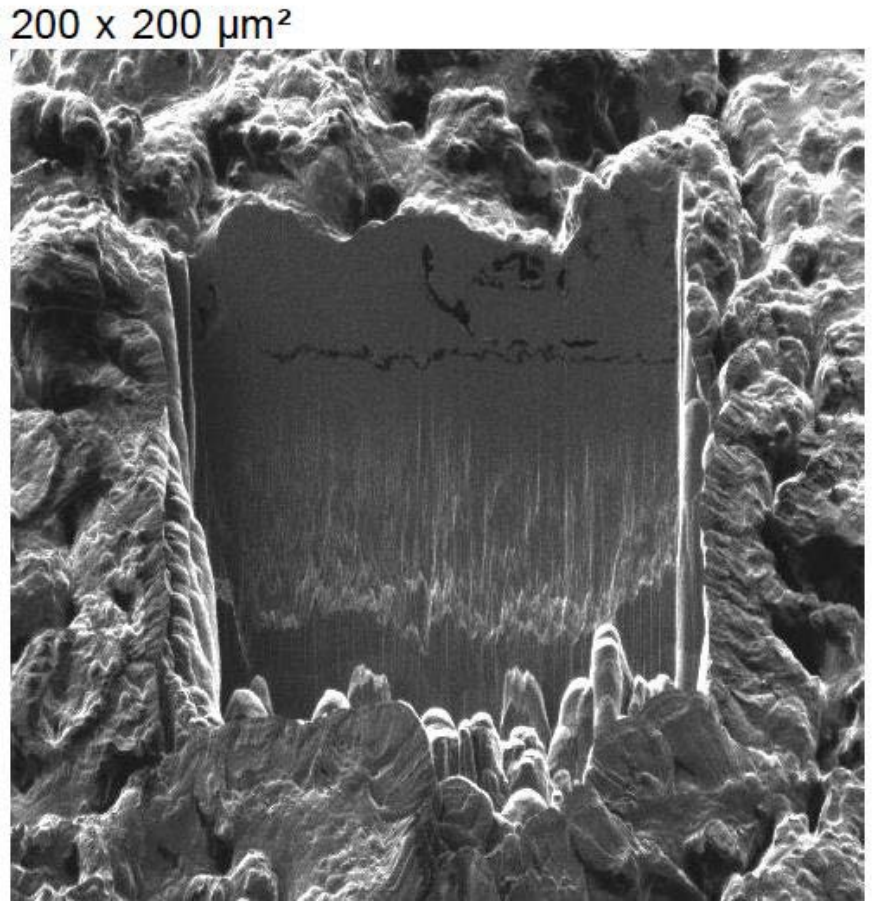

Figure 27 SEM Image of FIB trench created for ToF-SIMS Analysis

The positive ion data collected, observed in Figure 27, shows the different chemistries of the layers in the deposit. The bottom layer consisted of polysiloxanes [ $\underline{74-76}$ ], aliphatic and aromatic hydrocarbons, shown in Figure 28ii-iv. The silicone containing material is likely to have come from the antifoam in the fuel. The chemical mapping shows that the top layer of deposits is sodium rich. Sodium is likely to be in the form of salts bonded to carboxylates in the deposit, and may be the result of water contamination, or a poor quality biodiesel.

The negative ion chemical mapping of the trench is shown in Figure 29. The ions detected were $\mathrm{H}^{-}, \mathrm{OH}^{-}, \mathrm{O}^{-}, \mathrm{C}_{\mathrm{x}} \mathrm{H}_{\mathrm{y}}^{-}$, polysiloxanes, $\mathrm{PO}^{\mathrm{x}-}$ and $\mathrm{Cl}^{-}$. Oxygen species and hydrocarbons were found in the lower layer of the deposit. The horizontal crack in the deposit shown in Figure 27, had levels of $\mathrm{PO}^{\mathrm{x}-}$ and $\mathrm{C}^{\mathrm{l}-}$ present. The phosphate ions likely originate from lubricant oil additives.

This work gives novel insight into the formation of the external deposit on injector tip four. The crack in the deposit shows that the different chemistries that are seen for this sample do not bind together very well. It is likely that deposit formation will not remain of the surface for the entire lifetime of the injector. The deposit will form and break away or be strengthened or weakened by the fuel cycle causing either no problem to the engine function, reduce efficiency of engine or cause engine failure. As the engine experiences different fuels and additives then this would also have an effect in the adherence and removal of deposit.

The bottom of the deposit was not visible in this study and further work to fully characterise the layering to the injector surface is required. 


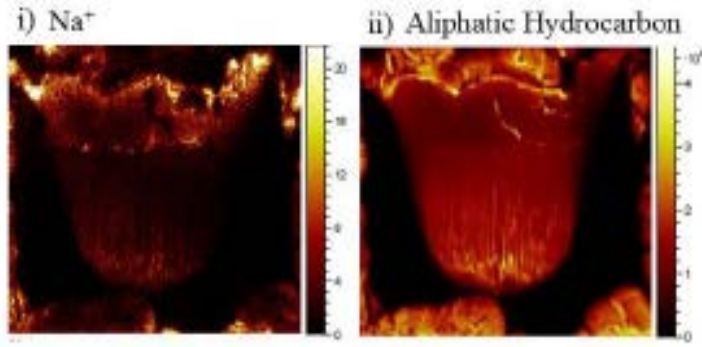

iii) Polysiloxane iv) Aromatic Hydrocarbon
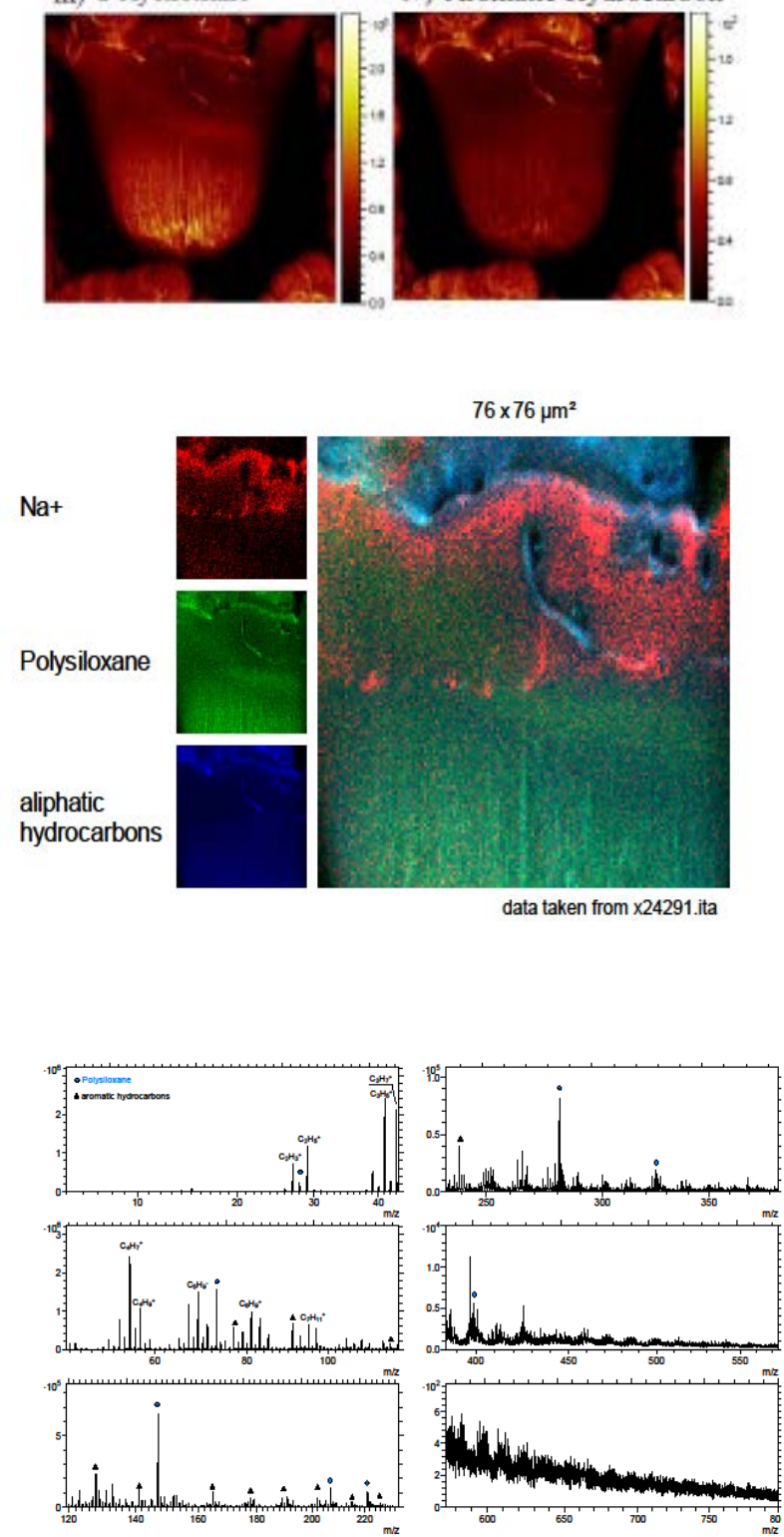

Figure 28 Positive Ion data

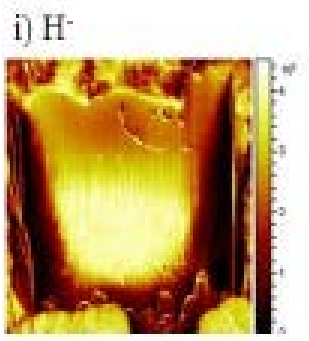

ii) Sum of: $\mathrm{O}^{-}, \mathrm{OH}^{-}$

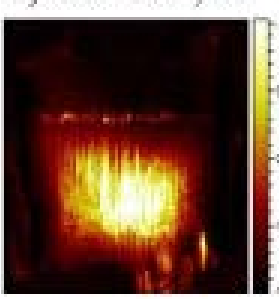

iv) $\mathrm{C}_{2} \mathrm{H}_{\mathrm{r}}$.
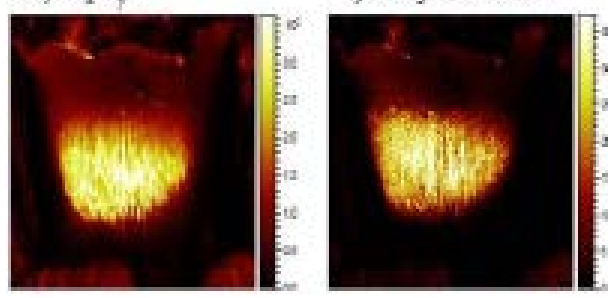

iii) $\mathrm{Cl}$

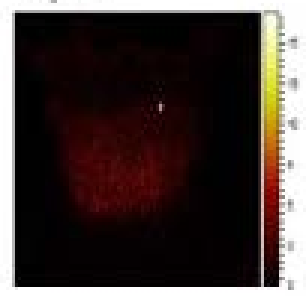

vi) Sum of: $\mathrm{PO}_{\mathrm{x}}$

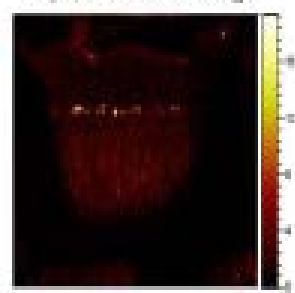

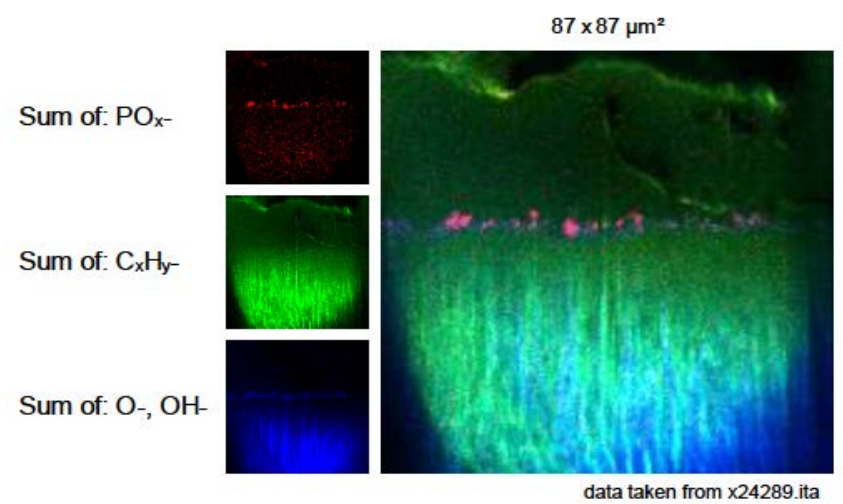
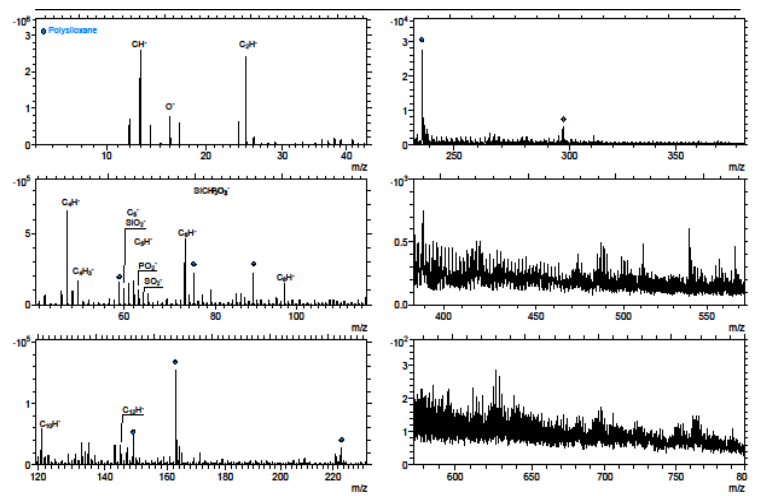

Figure 29 Negative ion data. 


\section{Deposit Control Additives}

Throughout the industry problem with injector deposits, another aspect of industry response has been the production of appropriate DCA additives to mitigate the issue in the field. Further it is clear from Figure 17 those areas of the world without DCA mitigation are seeing deposit problems. The historical effectiveness of the DCAs has been shown by the use of the industry standard CEC engine tests [20] described earlier. The XUD-9 test with and without DCA is shown in Table 6.

Table 6 XUD-9 data for fuel with and without DCA

\begin{tabular}{|l|c|c|c|c|c|}
\hline & \multicolumn{5}{|c|}{ XUD-9, \% Flow Loss } \\
\cline { 2 - 6 } & Nozzle 1 & Nozzle 2 & Nozzle 3 & Nozzle 4 & Average \\
\hline Base Fuel & 64 & 68 & 69 & 75 & 69 \\
\hline Base fuel + DCA & -1 & 1 & 0 & 0 & 0 \\
\hline
\end{tabular}

For the DW10-B engine test the keep clean and power loss/restoration are the important parameters, Figure 30 and 31 show the ability of DCAs to deliver keep clean and power loss clean up for the industry.

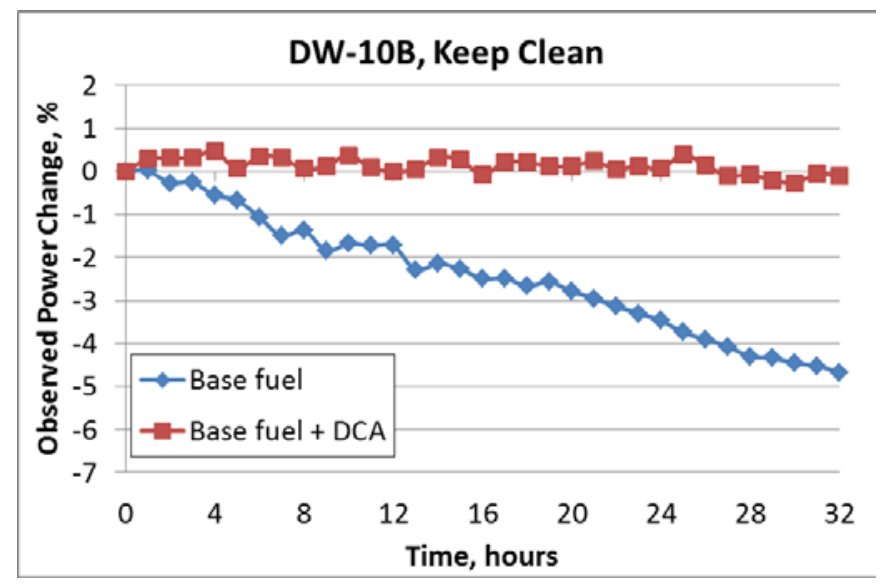

Figure 30 DW-10B Keep clean

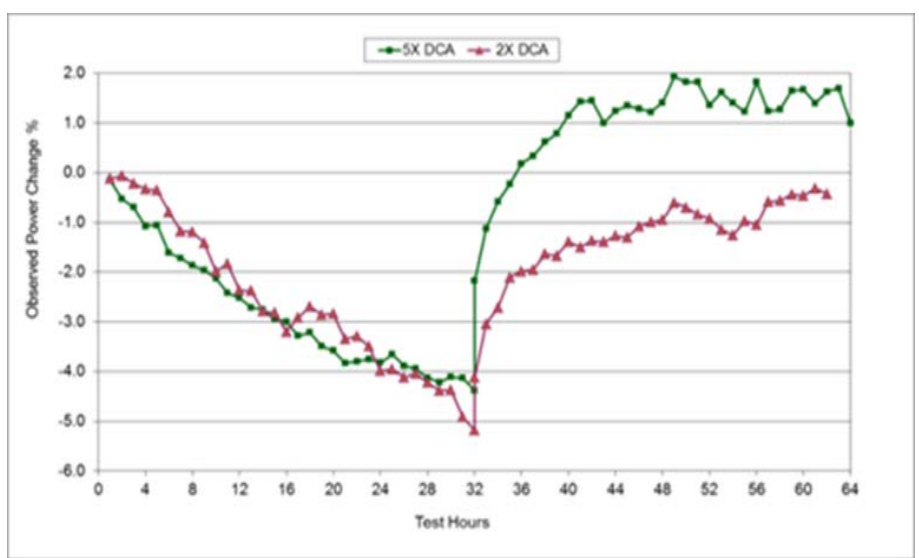

Figure 31 DW-10B Power loss and clean up

The standard procedure is for a Keep Clean test. The fuel contains 1 ppm zinc. Clean-Up testing is not part of the official CEC procedure but ran by laboratories worldwide. Generally zinc is included in both the Dirty-Up and Clean-Up stages of the test.

Page 16 of 20
In the latest industry test to be deployed sodium and organic acid or "non-commercial" low molecular weight PIBSI are added to the reference diesel fuel and significant injector sticking problems are observed.

The deviations in exhaust temperature as shown in figures 32 and 33 highlight the deviation from standard injector operation resulting in the low merit rating for each test. Conversely when the additive is introduced into the same fuels, (figures 34 and 35) and the engine test is ran under identical conditions, the injector operation remains within expected parameters and no major deviations in exhaust temperature are observed, resulting in the highest possible merit rating as measured in the DW10C engine.

A summary of the test data for both variations is shown in Figures 32-39 below.

“Non-commercial "Low molecular Weight PIBSI

\begin{tabular}{|l|l|l|r|}
\hline Basefuel & Contaminant & Additive & Merit Rating (M/10) \\
\hline Reference Fuel & $10 p p m$ Low MW PIBSI & None & 2.9 \\
\hline Reference Fuel & $10 \mathrm{ppm}$ Low MW PIBSI & Yes & 10 \\
\hline$\left(^{*}\right)=$ Low Molecular Weight Polyisobutylene Succinmide & & & \\
\hline
\end{tabular}

$(*)=$ "Non-commercial” Low Molecular Weight Polyisobutylene Succinmide

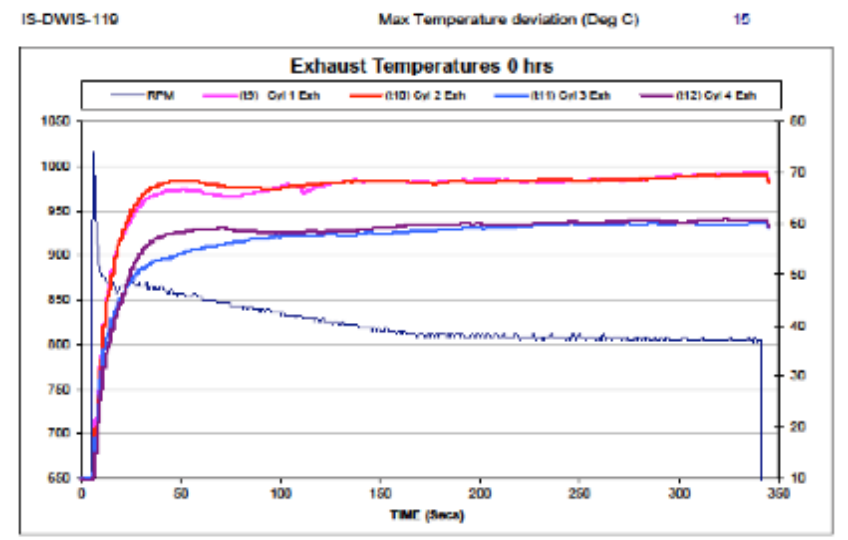

Figure 32: Exhaust Temperature Measurements - DW10C IDID Testing, Base fuel (Low MW PIBSI) at 0 hours

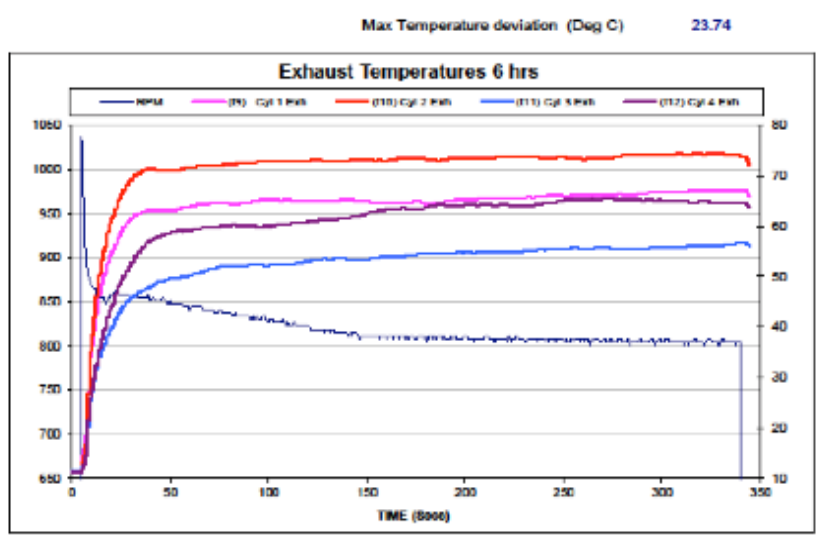

Figure 33: Exhaust Temperature Measurements - DW10C IDID Testing, Base fuel (Low MW PIBSI) at 6 hours 


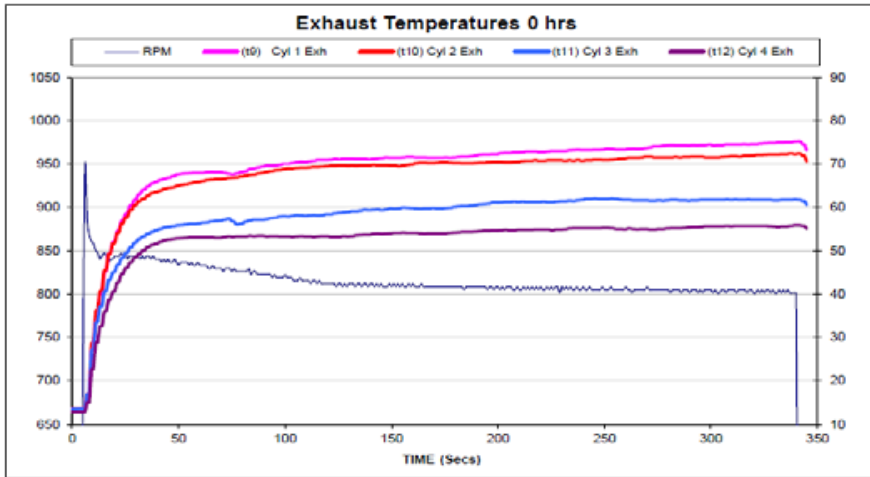

Figure 34: Exhaust Temperature Measurements - DW10C IDID Testing, Basefuel (Low MW “non-commercial PIBSI + Additive) 0 hours

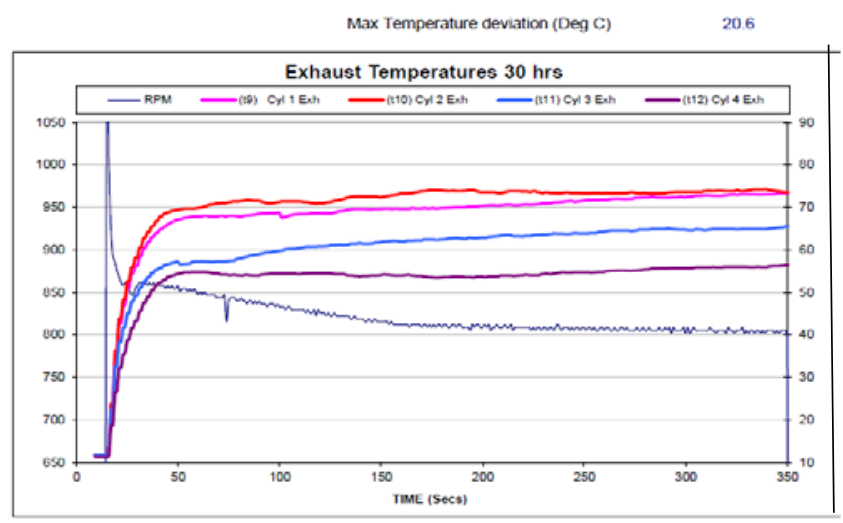

Figure 35: Exhaust Temperature Measurements - DW10C IDID Testing, Basefuel (Low MW “non-commercial” PIBSI) + Additive) 30 hours

\begin{tabular}{|l|l|l|r|}
\hline Basefuel & Contaminant & Additive & Merit Rating (M/10) \\
\hline Reference Fuel & $0.5 p p m$ Sodium* + 10ppm DDSA** & None & 4.0 \\
\hline Reference Fuel & $0.5 p p m$ Sodium* + 10ppm DDSA** & Yes & 10.0 \\
\hline & *Sodium as Sodium Naphthenate \\
& ** Dodecenylsuccinic Acid
\end{tabular}

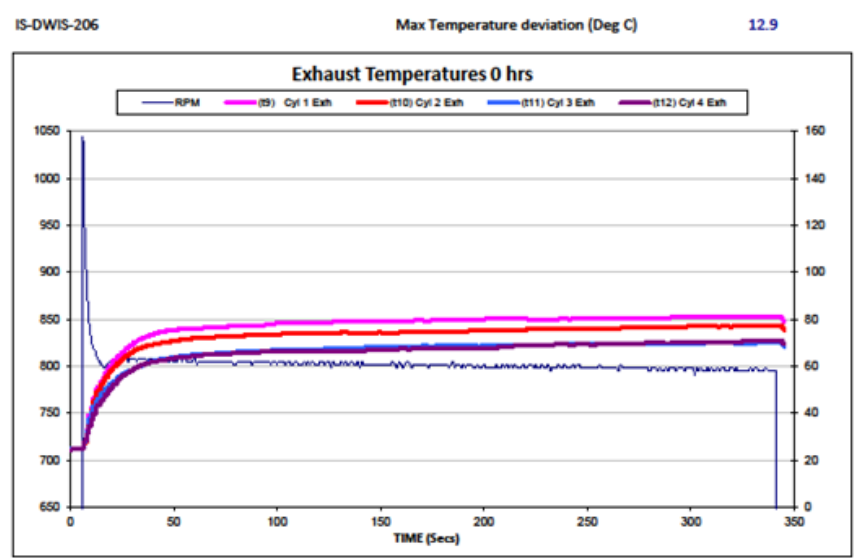

Max Temperature deviation (Deg C) $\quad 35.9$

Figure 36: Exhaust Temperature Measurements - DW10C IDID Testing, Base

Page 17 of 20

$03 / 01 / 2020$

\section{fuel (Na/DDSA) 0 hours}

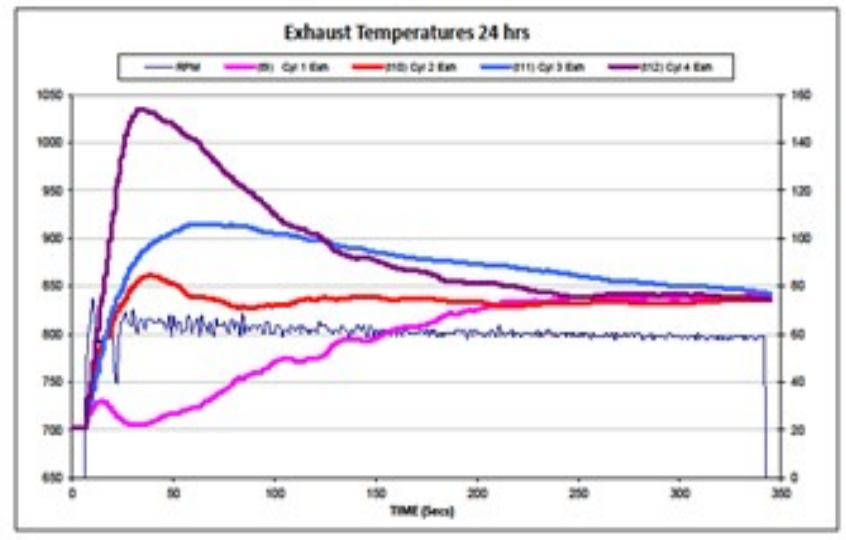

Figure 37: Exhaust Temperature Measurements - DW10C IDID Testing, Base fuel (Na/DDSA ) 24 hours

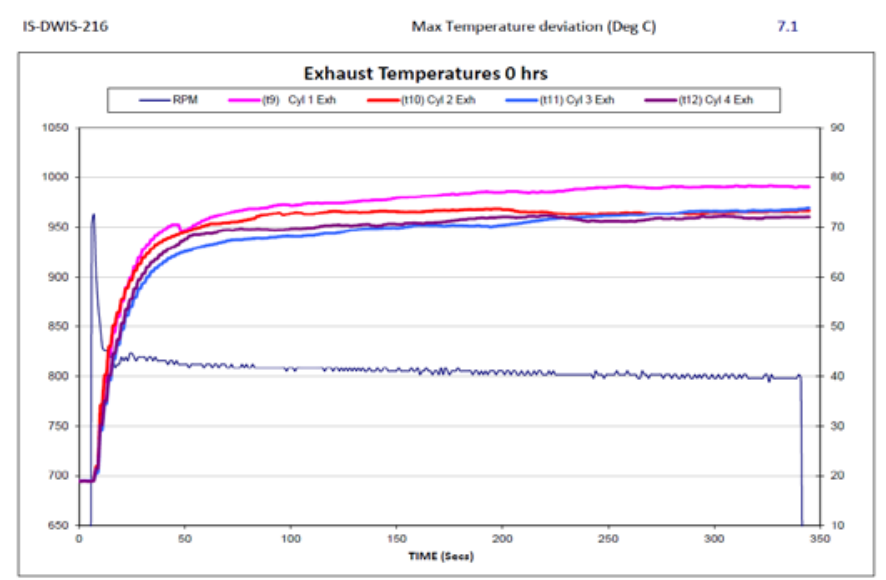

Figure 38 Exhaust Temperature Measurements - DW10C IDID Testing, Base fuel (Na/DDSA + Additive) 0 hours

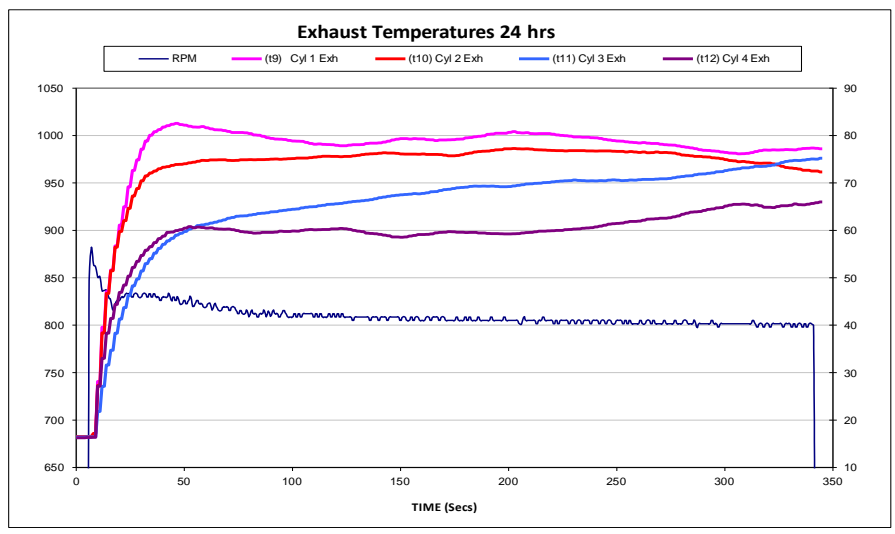

Figure 39 Exhaust Temperature Measurements - DW10C IDID Testing, Base fuel (Na/DDSA + Additive) 24hours

\section{Conclusions}

Historically industry has developed engine tests and analytical tests to measure the characteristics and the effect of injector deposits with 
the aim of mitigating the problems associated with them. Recent work has expanded upon that but clearly more work is required in both areas to build upon what has been learnt.

One of the recent advances in engine testing has seen the use of sodium naphthenate as a reagent. The complexity of its structure and solution properties, initial studies of which are described herein, indicate that its use will be problematic, as has been found.

The use of Tof-SIMS in the analysis of injectors has given a wealth of data to the characterization of IDID chemistries. However it is that very abundance of data that prevents its deployment to large number of samples. Its use in conjunction with PCA has been proven to be a successful tool used to analyze the deposits on eight injector needles and has rapidly identified similarities and differences in chemistries of IDIDs world-wide.

As previously described the power of Tof- SIMS to characterize IDID chemistries is well known. A new extension of the Tof-SIMS technique, FIB-ToF-SIMS has been used for the first time in injector deposit analysis and shown the EDID is layered in constitution in a similar manner to that of its IDID counterpart.

Deposit control additives continue to be developed to successfully mitigate and "clean up" diesel injector deposits.

In summary the industry continues to deploy new engine tests and modern analytical techniques and additive chemistries to understand mitigate measure and clean up diesel injector deposits and some of the latest advances are described in this paper. The introduction of new fuels and emission legislation will lead to challenges which these studies will inform.

\section{References}

1. Diesel ER.,"Arbeuitsverfahren und Ausfürungsart für Verbrennugskraftmaschinen” Pateschrift Nr 672071892

2. Barker, J., Richard, P., Snape, C., and Meredith, W., "Diesel Injector Deposits - An Issue That Has Evolved with Engine Technology," SAE Technical Paper 2011-01-1923, 2011, https://doi.org/10.4271/2011-01-1923.

3. Richards P ., ed "'Influence of Diesel Fuel Composition on Stability and Engine deposits", SAE Automotive Fuels Reference Book $3^{\text {rd }}$ edition 2014 ISBN 978-0-7680-0638-4.

4. H Hoffmann "A Contribution to the Investigation of Internal Diesel Injector Deposits” Dissertation RWTH Aachen University Shaker Verlag 2018, Aachen ISBN978-3-8440-5953$\underline{3 .}$

5. Edney M.K, Barker J, Reid J, Scurr D.,J. Snape C.,’'Recent Advances in the Analysis of GDI and Diesel Fuel Injector Deposits.” Fuel, Volume 272, 15 July 2020, 117682; 1-9 https://doi.org/10.1016/j.fuel.2020.117682

6. SMMT European engine emission standards.http://www.smmt.co.uk/industrytopics/environment/intro/european-engine-emission-standards/ (accessed 13/04/2016).

7. Miller P., Solomon , M.,, “A Brief History of TechnologyForcing Motor Vehicle Regulations EM 4-8 June, 2009.

8. United States Emission Standards. https://www.epa.gov/regulations-emissions-vehicles-andengines (accessed 13/04/2020).

9. $\quad$ Fritz, S., Hedrick, J., and Rutherford, J., "Locomotive Emissions Measurements for Various Blends of Biodiesel Fuel," SAE
Technical Paper 2013-24-0106, 2013, https://doi.org/10.4271/2013-24-0106.

10. Fink C., Schumann U.,Junk R.,Nowotny M.,: Harndorf H.: Internal Diesel Injector Deposits-Causes and Measures with the Focus on Marine Applications and Fuels. Cimac 28, 217. 2016.

11. Banning M., Barker J., Mulqueen S.,’The Nature and Cause of Internal Diesel Injector Deposits and the Effectiveness of Fuel additives.” Cimac 28- 192, 2016.

12. Schwab, S., Bennett, J., Dell, S., Galante-Fox, J. et al. : Internal Injector Deposits in High-Pressure Common Rail Diesel Engines, SAE Int. J. Fuels Lubr. 3(2):865-878, 2010.

13. Caprotti, R., Bhatti, N., and Balfour, G., : Deposit Control in Modern Diesel Fuel Injection Systems, SAE Int. J. Fuels Lubr. 3(2):901-915, 2010.

14. Routhwaite N., J., Williams R., McGivery, Jiang, J., Giulliani F., and Britton,M., "A Chemical and Morphological Study of Diesel Injector Nozzle Deposits- Insights into their Formation and Growth Mechanisms” SAE Int. J Lubr, 10(1):2017, https://doi:.org10.4271/2017-01-0798.

15. Arondel, M., Rodeschini, H., Lopes, M., and Dequenne, B.: Fuel Additives for Reduction of Internal Diesel Injectors Deposits (IDID, "lacquering”): A Critical and Priority Route, SAE Technical Paper 2012-01-1687, 2012.

16. Lacey, P., Gail, S., Kientz, J., Milovanovic, N. et al.: Internal Fuel Injector Deposits," SAE Int. J. Fuels Lubr. 5(1):132-145, 2012.

17. Lacey, P., Gail, S., Kientz, J., Benoist, G. et al.,"Fuel Quality and Diesel Injector Deposits, SAE Int. J. Fuels Lubr. 5(3):11871198, (2012)

18. Painsi, M. and Grafl, A. :Understanding Internal Diesel Injector Deposits: New Insights from Laboratory Experiments TAE 9th International Colloquium,121-139, 2013.

19. Tanaka, A., Yamada, K., Omori, T., Bunne, S. et al. Inner Diesel Injector Deposit Formation Mechanism,SAE Int. J. Fuels Lubr. 6(3):755-761, 2013

20. http://www.cectests.org/, visited March 2020.

21. Panesar A., Martens A., Jansen L., Lal S., Ray D. and Twilley M. "Development of a New Peugeot XUD9 10 Hour Cyclic Test to Evaluate the Nozzle Coking Propensity of Diesel Fuels" SAE paper 2000-01-1921,2000.

22. Hawthorne M., Roos J. W. and Openshaw M. J. "Use of Fuel Additives to Maintain Modern Diesel Engine Performance with Severe Test Conditions" SAE paper 2008-01-1806 39,2008.

23. Montagne X., Herrier D. and Guibet J-C. "Fouling of Automotive Diesel Injectors Test procedure, influence of Composition of Diesel Oil and Additives" SAE paper 8721181987.

24. Wo, H., Dearn, K.,D., Song, R., Hu, E., and Hu, X. "Morphology Composition and Structure of Carbon deposits From Diesel and Biomass oil/diesel blends on a Pintle -type Fuel injector nozzle”. Tribology Int. 91, 189-196, 2015.

25. Risberg $P$ and Alfredson S ., "The Effect of Zinc and other Metal Carboxylates on Nozzle Fouling “ SAE Technical Paper 2016-01-0837, 2016,https:// doi:org 10.4271/2016-01-0837.

26. Sykes D, de Sercey, G., Gold., M., Pearson, R and Crua, C. "Visual Analyses of End Injection Liquid Structures and the Behaviour of Nozzle Surface Bound Fuel in Direct Injection Diesel Engine” SAE Technical Paper 2019-01-0059, 2019, https:// doi:10.4271/2019-01-0059.

27. Bernemyr, H., Csontos, B., Hittig, H., and Forsberg O., „Study of Nozzle Fouling: Deposit Build-Up and Removal“ SAE Technical Paper 2019-01-2231 2019.

28. Stepian Z "Investigations of Injector Deposits in Modern Diesel Engines” Combustion Engines 9-20,16592,2016. https://doi:10.19206/CE-2016-202.

Page 18 of 20 
29. Stepian Z., "Deterioration of Fuel Injection Parameters as A Result of Common Rail Injectors Deposit formation”MATEC WEB of Conf118.00002 2017 VII Int. Cong.on Combustion Engines.

30. Stepian S “ Zinc as a Catalyst Supports Process of Diesel Injector deposit Formation” Nafta -Gaz , ROK LXXIV no2 (2018). https://doi.org: 10:18668/NG.2018.02.07.

31. Stepian, Z., Mazanek, A., and Suchecki A., "Impact of Fuel On Real Diesel Injector Performance in field test “. J. Automobile Engineering 232(8) 1047-1059 2018

32. Gopalan, K., Chuck, C.J., Roy-Smith, C., and Bannister C.D. "Assessing the Impact of FAME and Diesel Fuel Composition on Stability and Vehicle Filter Blocking”.SAE Int . J Advances \& Curr. Prac. In Mobility 1(1):284-290, 2019, https://doi:10.4271/2-019-01-0049.

33. Corbett C. J., MCintosh, A, J. S., Gee, M. and Hallett J.P., "Use of Ionic Liquids to Minimise Sodium Induced Internal Disel Injector deposits (IDIDs)”. Mol. Syst. Des. Eng.,(2018), 23, 397.

34. Ullmann, J., Geduldig, M., Stutzenberger, H., Caprotti, R. et al.:Investigation into the Formation and Prevention of Internal Diesel Injector Deposits, SAE Technical Paper 2008-01-0926, 2008.

35. Reid, J. and Barker, J., "Understanding Polyisobutylene Succinimides (PIBSI) and Internal Diesel Injector Deposits," SAE Technical Paper 2013-01-2682, 2013, https://doi:10.4271/2013-01-2682.

36. Fang X, and Galante-Fox J “Diesel fuel additive” US patent 2011/030828 A1.

37. http://crcao.org/wp-content/uploads/2019/09/CRC-DP-0417_Final-Report_Rev-4.pdf.” CRC Internal Diesel Injector Deposit (IDID) Test , Hardware , Fuel and additive Evaluations.."

38. https://www.cen.eu/ cent r 15367-1 Liquid petroleum Products Guideline for Good Housekeeping Part 1Automotive Diesel fuels.

39. https://astm.org/_ “Diesel Cleanliness Workshop” June 2015

40. Schwab, S., Bennett, J., Dell, S., Galante-Fox, J. et al. Internal Injector Deposits in High-Pressure Common Rail Diesel Engines, SAE Int. J. Fuels Lubr. 3(2):865-878, 2010

41. Cardenas Almena, M., Lucio Esperilla, O., Martin Manzanero, F., Murillo Duarte, Y. et al. : Internal Diesel Injector Deposits: Sodium Carboxylates of C12 Succinic Acids and C16 and C18 Fatty Acids, SAE Technical Paper 2012-01-1689, (2012)

42. Reid, J., Cook, S., and Barker, J.:Internal Injector Deposits From Sodium Sources, SAE Int. J. Fuels Lubr. 7(2):436-444, (2014).

43. Lacey, P., Gail, S., Kientz, J., Benoist, G. et al.,"Fuel Quality and Diesel Injector Deposits, SAE Int. J. Fuels Lubr. 5(3):11871198, 2012.

44. Trobaugh C, Burbank C, Zha Y, Whitacre S, Corsi, C and Blizzard N. :Internal Diesel Injector deposits: Theory and Investigations into Organic and Inorganic Based Deposits SAE technical paper 2013-01-2670. (2013)

45. Joseph J., T., "Sodium Contamination in Diesel Fuels” Fuel, , Sept. 66-68, 2015.

46. Barker, J., Richards, P., Pinch, D., and Cheeseman, B., "Temperature Programmed Oxidation as a Technique for Understanding Diesel Fuel System Deposits," SAE Int. J. Fuels Lubr. 3(2):85-99, 2010, https://doi.org/10.4271/2010-01-1475.

47. Barker, J., Snape, C., and Scurr, D., :Information on the Aromatic Structure of Internal Diesel Injector Deposits From Time of Flight Secondary Ion Mass Spectrometry (ToF-SIMS), SAE Technical Paper 2014-01-1387, 2014.

48. Lau, K., Junk, R., Klingbeil, S., Schümann, U. and Streibel, T..: Analysis of Internal Common Rail Injector Deposits via
Thermodesorption Photon Ionization Time of Flight Mass Spectrometry Energy \& Fuels, 29(9), pp.5625-5632, 2015.

49. Venkkataraman R., Eser S.: Characterisation of Deposits Formed On Diesel Injectors in Field Test and from Thermal Oxidative Degradation of n-hexadecane in a Laboratory Reactor,. Chemistry Journal,2 , 25-35, 2008.

50. Cook S., and Richards P.: Possible Influence of High Injection Pressure on Diesel Fuel stability: A Review and Preliminary Study. SAE paper 2009-01-1878, 2009.

51. Beaver B., Gao L., Burgess-Clifford C,.Sobkowiak, M On the Mechanisms of Formation of Thermal Oxidative Deposits in Jet Fuels. Are Unified Mechanisms Possible for Both Storage and Thermal Oxidative Deposit Formation for Middle Distillate Fuels? Energy and Fuels, 19, 4, 1574-1579, 2005.

52. Barker, J., Snape, C., and Scurr, D., "A Novel Technique for Investigating the Characteristics and History of Deposits Formed Within High Pressure Fuel Injection Equipment," SAE Int. J. Fuels Lubr. 5(3):1155-1164, 2012, https://doi.org/10.4271/2012-01-1685.

53. Barker J ., Scurr D., Snape C., Diesel Deposits TAE 9th International Colloquium Fuels Conventional and Future Energy for Auto-mobiles Jan 152013.

54. Dallanegra, R. and Caprotti, R., "Chemical Composition of Ashless Polymeric Internal Diesel Injector Deposits," SAE Technical Paper 2014-01-2728, 2014, https://doi.org/10.4271/2014-01-2728.

55. Feld, H. and Oberender, N., "Characterization of Damaging Biodiesel Deposits and Biodiesel Samples by Infrared Spectroscopy (ATR-FTIR) and Mass Spectrometry (TOFSIMS)," SAE Int. J. Fuels Lubr. 9(3):717-724, 2016, https://doi.org/10.4271/2016-01-9078

56. Barker, J. Reid J. Piggott, M. Fay, M. Davies, A. Parmenter, C. Weston, C. Snape, C. Scurr, D. Angel-Smth, S. : The Characterisation of Diesel Internal Injector Deposits by Focussed Ion-Beam Scanning Electron Microscopy (FIB-SEM), Transmission Electron Microscopy (TEM), Atomic Force Microscopy (AFM) and Raman Spectroscopy SAE Technical paper 2015-01-1826. 2015.

57. Barker J., Reid J.,Snape C., Scurr D.,Piggott M., Fay M., Davies A., Parmenter C., and Weston N. "Internal Injector deposits (IDID).” TAE 11th International Colloquium Fuels Conventional and Future Energy for Auto-mobiles Jun 272017.

58. Ullmann J. and Stutzenberger H., "Internal Diesel Injector Deposit Formation - Reproduction in Laboratory, System Bench and Engine Tests,” TAE Fuels 9th International Colloquium, January 2013.

59. Lacey, P., Gail, S., Grinstead, D., Daveau, C. et al., "Use of a Laboratory Scale Test to Study Internal Diesel Injector Deposits," SAE Technical Paper 2016-01-2247, 2016, https:// doi:org10.4271/2016-01-2247.

60. Ullmann, J., Geduldig, M., Stutzenberger, H., Caprotti, R. et al.,"Investigation into the Formation and Prevention of Internal Diesel Injector Deposits," SAE Technical Paper 2008-01-0926, 2008, https://doi.org:10.4271/2008-01-0926.

61. Berndt,S., Schumann, U,. Sadlowski, T., and Bucholz B,. "Development of a Laboratory Test for the Deposit Forming Tendency of Diesel Fuels” ATH offhighway 01 50-55 2018.

62. Barker, J., Reid, J., Angel Smith, S., Snape, C. et al., "The Application of New Approaches to the Analysis of Deposits from the Jet Fuel Thermal Oxidation Tester (JFTOT)," SAE Int. J. Fuels Lubr. 10(3):2017,https:// doi.org:10.4271/2017-01-2293

63. De Goede S., Barbour, R., Velaers A., Sword B., Burton, D., and Mokheseng K., "The Effect of Near-Zero Aromatic Fuels on

Page 19 of 20 
Internal Diesel Injector Deposit Test Methods” SAE Int. J, Fuels Lubr 10(1):2017,https:// doi.org:10.4271/2017-01-0807.

64. Hoang A, T., and Le A. T., "A review on Deposit Formation in the Injector of Diesel Engines Running on Biodiesel " Energy Siurces Part A: Recovery, Utilization, and EnvironmentalEffects 41:5, 584-599 ,2019.

https://doi.org:10.1080/15567036.2018.15020342.

65. Alves Fotunato M., Lenglet, F,. Ben Amara, A., and Starck l., “Are Internal Diesel Injector Deposits (IDID) Mainly Linked to Biofuel Chemical Composition or.and Engine Operation Condition?. SAE Technical Paper 2019-01-0061.

66. Suwannamit S., Ngammoh J,. Funahashi M., Tasaki M., Krissanasaeranee M.,, Porntangjitlikit S., Silapakampeerapap, S., Wuttimongkolchai A., Chiampradit N., The precipitation of biodiesel impurities at low temperature and its effect on fuel filters. Technical Paper JSAE 20199028 SAE 2019-01-2188.

67. Gauld R. M., McLellan, R., Kennedy, A. R., Barker J., Reid J., Mulvey R., Backbone Reactivity of Lithium $\beta$-Diketiminate (NacNac) Complexes with CO2, tBuNCO and iPrNCO, 25, 64 ,14728-14734, 2019.

68. Qian, W. K. Robbins, C. A. Hughey, H. J. Cooper, R. P. Rodgers, A. G. Marshall, Energy \& Fuels, 156), 1505-1511, 2001

69. J. S. Clemente, P. M. Fedorak, Chemosphere, 60, 585-600, 2005.

70. P. N. Nelson, H. A. Ellis, J. Mol. Struct., 1075, 299-310, 2014.

71. S. Bachmann, B. Gernert, D. Stalke, Chem. Commun., 52, 12861-12864, 2016.

72. Pearson K., "On Lines and Planes of Closest Fit to Systems of Points in Space “ Philosphical Magazine, ,2 (11) 559-572,1901. https://doi.org:10.1080/1478644010946272

73. .Barker, J., Reid, J., Snape, C., Scurr, D. et al.: Spectroscopic Studies of Internal Injector Deposits (IDID) Resulting from the Use of Non-Commercial Low Molecular Weight Polyisobutylenesuccinimide (PIBSI), SAE Int. J. Fuels Lubr. 7(3):762-770, 2014

74. Oran U., U.E., Wirth T., Unger W.E.S., Poly-Dimethyl-Siloxane (PDMS) contamination of Polystyrene (PS) Oligomers Samples: A Comparison of Time-of-Flight Static Secondary Ion Mass Spectrometry (ToF-SIMS) and X-ray Photoelectron Spectroscopy (XPS) Results. Applied Surface Science,. 227(1): p. 318-324, 2004.

75. Vickerman J. C., B.D., Henderson A., The Static SIMS Library. Surface Spectra Manchester 1997.

76. Delcorte A., B.S., Poleuris C., Troosters M., Improvement of Metal Adhesion to Siliconfilms: A ToF-SIMS Study. Adhesion Aspects of Thin Films,. 2: p. 155-166, 2004.

\section{Contact Information}

James Barker

Tel: +441513553611

Email: jim.barker@Innospecinc.com

Innospec Limited

Innospec Manufacturing Park

Oil Sites Road,

Ellesmere Port

Cheshire CH65 4EY

England

http://www.innospecinc.com

\section{Acknowledgments}

The authors would like to acknowledge Mr. David Knight (Innospec) for disassembling the injectors and Mr. Mark Wheeler (Innospec) for engine test data. EPSRC for funding Sarah Angel Smith's Engineering Doctorate through the Centre for Doctoral Training in Efficient Fossil Energy Technologies University of Nottingham EPSRC for funding Richard Gauld University of Strathclyde. 